\begin{tabular}{|l|l|l|l|l|l|}
\hline MUNIBE Antropologia-Arkeologia & $n^{\circ} 69$ & $191-210$ & DONOSTIA & 2018 & ISSN 1132-2217 • eISSN 2172-4555 \\
\hline
\end{tabular}

\title{
El conjunto de círculos pirenaicos de Ondarre en la Sierra de Aralar (Gipuzkoa): de monumento funerario a hito ganadero
}

\author{
The Pyrenean stone circles from Ondarre, Aralar Mountain Range \\ (Gipuzkoa, Basque Country, Spain). Funerary structures \\ in origin related later to livestock breeding
}

PALABRAS CLAVES: Ritual funerario, incineración, País Vasco, Bronce Final, haustarri. GAKO-HITZAK: Ehorzketa errituala, errausketa, Euskal Herria, Azken Brontzea, haustarri KEY WORDS: Funerary ritual, cremation, Basque Country, Late Bronze Age, shieling marking stone.

\section{José Antonio MUJIKA-ALUSTIZA(a), Jaione AGIRRE-GARCíA(b), Erik ARÉVALO-MUÑOZ(a), José Miguel EDESO-FITO(c), Ane LOPETEGI-GALARRAGA ${ }^{(c)}$, Iñigo ORUE-BELTRAN DE HEREDIA(f), Sebastián PÉREZ-DíAZ(d), Mónica RUIZ-ALONSO(d), Daniel RUIZ-GONZALEZ ${ }^{(\mathrm{a})}$ y Luis ZALDUA-ETXABE ${ }^{(\mathrm{e}) 1}$}

\section{RESUMEN}

En este artículo se presentan tres crómlechs excavados en la Sierra de Aralar. Ondarre I tiene un diámetro de siete metros y está conformado por 35 testigos. El túmulo de tierra tiene $45 \mathrm{~cm}$ de altura. En su zona central había 4 losetas de caliza, y una pequeña cubeta con huesos incinerados, pertenecientes a dos individuos y abundantes carbones.

A seis metros de distancia está Ondarre II, que tiene un diámetro de 4,5 metros y conserva sólo 15 de los testigos. En el sondeo se han localizado pequeñas manchas de carbón en el centro y algún sílex.

El crómlech de Ondarre III tenía un diámetro de unos 9 metros, pero está muy incompleto, ya que conserva sólo cuatro testigos. Junto a sus bases y en la zona central se hallaron carbones. Uno de ellos fue reutilizado como haustarri (hito ganadero), según un documento del siglo XIX.

Las fechas radiocarbónicas los sitúan en el Bronce Final.

\section{LABURPENA}

Aralarko Mendietan indusitako lehenengo hiru baratzeak aztertzen dira artikulu honetan. Ondarre I-ek 7 metroko diametroa du eta 35 lekukok eratzen dute. Tumuluak, lurrezkoa, $45 \mathrm{~cm}$-ko altuera du. Bere erdialdean kareharrizko lau harlauzatxo eta bi gizabanakoei dagozkien giza hezur erraustuak eta ikatza zituen zulogune bat zegoen.

Bertatik sei metrora Ondarre II dago, 4,5 metroko diametroa du eta soilik 15 lekuko kontserbatzen ditu. Zundaketan kimo-orban txikiak eta suharriren bat aurkitu ziren.

Ondarre III harrespilak 9 metroko diametroa dauka, baina ez dago osorik, lau lekuko baino ez baititu kontserbatzen. Lekukoen oinarrian eta erdialdean ikatza aurkitu zen. Lekukoetako bat haustarri moduan berrerabilia izan zen, XIX. mendeko dokumentu batean agertzen den moduan. Datazio erradiokarbonikoen arabera, Azken Brontze Arokoa da.

\section{ABSTRACT}

The stone circle and the burial mound stone circles Ondarre I, II and III are three funerary structures related to cremation we excavated in the western side of the Aralar mountain range. They are the first testimony of cremation as funerary ritual we have to the west of the river Leitzaran (Gipuzkoa, Navarre), together with the stone circles we have excavated in Beaskin hilltop. Cremation funerary structures (such as baratze or stone circles or Pyrenean stone circles) are unknown or scarce in geological areas of the Pyrenees that not have hard lithology (for instance schist or granite), due to conservation problems and, consequently, it is difficult to identify them in areas with softer rocks as limestones. These structures have been dated to Late Bronze Age and Iron Age using radiocarbon dating.

Ondarre I burial-mound stone circle has a diameter of 7 meters and 35 standing stones. Most of these standing stones are different varieties of limestone and only two are made of sandstone. The mound is built with soil and it is $45 \mathrm{~cm}$ thick. In the middle there were a small pit was burnt bones were placed, a wide carbonated stain and 4 limestone flagstones (possibly the broken parts of one original stone). Two individuals

\footnotetext{
1(a) Facultad de Letras (UPV-EHU). C/ Tomás y Valiente s/n. Vitoria-Gasteiz. joseantonio.mugica@ehu.eus; erik.arevalo@ehu.eus; daniel.ruiz@ehu.eus (b) BIBAT Arabako Arkeologia Museoa / Museo de Arqueología de Álava. Aiztogile kalea, 54. 01001. Vitoria/Gasteiz. jagirregarcia@araba.eus (c) Escuela Universitaria de Ingeniería -E.U.I.-, UPV-EHU. C/ Nieves Cano, 12. 01006. Vitoria-Gasteiz. josemiguel.edeso@ehu.es; ane.lopetegui@ehu.eus (d) G. I. Arqueobiología. Instituto de Historia. Centro de Ciencias Humanas y Sociales (CCHS). Consejo Superior de Investigaciones Científicas (CSIC). Albasanz, 26-28. 28047. Madrid. monica.ruiz@cchs.csic.es; sebastian.perez@cchs.csic.es.

(e) Comisión de Onomástica de Euskaltzaindia. luismarizaldua@gmail.com

(f) innigo.orue@gmail.com
} 
were identified from the small human bone bits retrieved. Among the charcoal fragments, Fraxinus is the most abundant species, followed by Fagus, Corylus and smaller testimonies of other trees like alder and maple. One of those charcoal fragments dated to $2740 \pm 30 \mathrm{BP}$ and another one near the biggest standing stone $2830 \pm 30 \mathrm{BP}$. In the centre of the stone circle there was no evidence of funerary objects.

Six meters far from Ondarre I, there is Ondarre II. The structure has a diameter of 4.5 meters and only 15 standing stones are preserved (all of them made of limestone). During the excavation small charcoal fragments were found and 260 of them were identified. Rosaceae are specially represented (pomoidea among them), followed by beech tree, birch, hazel tree and much fewer alder tree, Salix/Populus, ash, holly and deciduous Quercus species. One of the charcoal fragments dated to $2800 \pm 30 \mathrm{BP}$.

Ondarre III stone circle had a diameter of 9 meters, but it was very badly preserved (we found only 4 standing stones made of limestone). At the bottom of the standing stones charcoal fragments were found and as well as coal stains in the centre of the circle, from which 61 small charcoal fragments were identified: Rosaceae, Fagus sylvatica, deciduous Quercus species and alder tree, willow or birch trees, and hazel trees. Some flint splinters were found and a pottery sherd, maybe from a non-preserved funerary urn. One of the charcoal fragments date to $2760 \pm 30 \mathrm{BP}$. The biggest standing stone of the circle was later reused as a shieling marking stone (haustarri or hausterretza), as appears in a $19^{\text {th }}$ century map and previous written documents. These stones were used to mark the land in livestock breeding contexts. At the bottom of this standing stone there was a stain full of charcoal fragments (Corylus, Prunus tp. avium and Salix/Prunus were identified). This "hearth" dated to $2821 \pm 30 \mathrm{BP}$

\section{INTRODUCCIÓN}

Hasta el descubrimiento y excavación del crómlech tumular de Ondarre I el ritual de incineración era desconocido en la Sierra de Aralar. Su detección se produjo por la semejanza de uno de sus testigos con un haustarri o piedra cenizal (< euskera hausterretza, lugar de cenizas), mojón central identificativo del sel, que destacaba en el pequeño valle de Ondarre. La prospección intensiva permitió descubrir, junto al citado, al menos otro crómlech tumular (Ondarre II), así como verificar posteriormente que el haustarri enhiesto, que durante siglos ordenó el aprovechamiento ganadero de ese sector del territorio, era en realidad el testigo más destacado del crómlech Ondarre III en su emplazamiento original.

La excavación de estas tres estructuras funerarias, de las que sólo Ondarre I ha aportado restos humanos, ha permitido documentar la ocupación de este espacio durante el Bronce Final-Edad del Hierro. Ésta, probablemente, generaría la necesidad de reordenar la gestión de los distintos recursos disponibles (pastos, frutos, agua, minerales en otros sectores, etc.) mediante la colocación de hitos visibles en el territorio. Es presumible que con anterioridad ese papel lo desempañasen el dolmen de Argarbi y más tarde, también, la cista de Ondarre.

\section{EL EMPLAZAMIENTO DE ONDARRE ${ }^{1}$}

La Depresión de Ondarre se localiza entre el cierre periclinal del núcleo Jurásico y el flanco meridional del Anticlinal de Aralar, donde se ha originado una depresión fluvio-kárstica de 1275 m de largo y 540 m de ancho de dirección general N-S. Todo el conjunto está drenado por dos pequeños cursos torrenciales permanentes, uno de los cuales incide en el relleno, que desaparecen en la sima-sumidero de Ondarre.

Desde el punto de vista litológico se diferencia la mitad norte caracterizada por materiales calizos del Dogger-Malm, donde se desarrollan importantes formas kársticas. En la mitad meridional, que presenta un modelado fluvial, predominan las areniscas, margas, etc. (Jurásico terminal-Barremiense-Aptiense) (Lopetegi-Galarraga et al., 2012).

Esta depresión kárstica ha sido históricamente una zona de intenso aprovechamiento ganadero en la época estival, pero sin embargo, era un vacío arqueológico en lo que se refiere al poblamiento prehistórico. Las prospecciones realizadas detectaron estructuras históricas en la ladera norte que desciende a la "Oyada de Ondarre" (Ondarreko Zuloa) no señaladas en el plano, además de algunos restos musterienses descontextualizados (lasca levallois, núcleo discoidal) recogidos en la zona. Ya en la base de la ladera hay una cista o cofre de tradición dolménica datada en la Edad del Bronce.

Esta cista está separada de la zona más llana del valle de Ondarre por un abarrancamiento erosivo situado en el borde septentrional de la dolina que rehunde su fondo (de dirección W-E), y por el que discurre un hilo de agua entre el sumidero y la sima. De norte a sur encontramos diversos elementos de sumo interés, tales como un monolito de naturaleza desconocida, que se localiza en el borde de la dolina mencionada anteriormente.

Se trata de un bloque calizo de forma "piramidal", irregular, que estaba parcialmente cubierto por brezo y argoma. Por su emplazamiento, alejado de los estratos calizos próximos, solo cabe proponer un aporte humano. Da la impresión de que estuvo colocado verticalmente en ese punto, ya que a sus pies había pequeños fragmentos desprendidos del mismo, así como algún otro resto mayor en la pendiente que desciende hacia la sima de Ondarre. Sus dimensiones son: 80 (Alt.) $X$ 53 (A) X 22 (E.) cm. Durante la limpieza superficial realizada junto a su base no se halló material arqueológico alguno. No hay elementos que permitan concretar su cronología, ni su posible relación con los crómlechs. A continuación, más al sur se encuentra el monolito enhiesto documentado en el siglo XIX como haustarri de un sel citado desde el siglo XV y que originalmente era el testigo más destacado del baratze o cromlech Ondarre III, y por lo que parece, de todo el conjunto. Fi-

\footnotetext{
${ }^{1}$ Variante oral, sin normativizar, del topónimo Pikuetaondarra.
} 


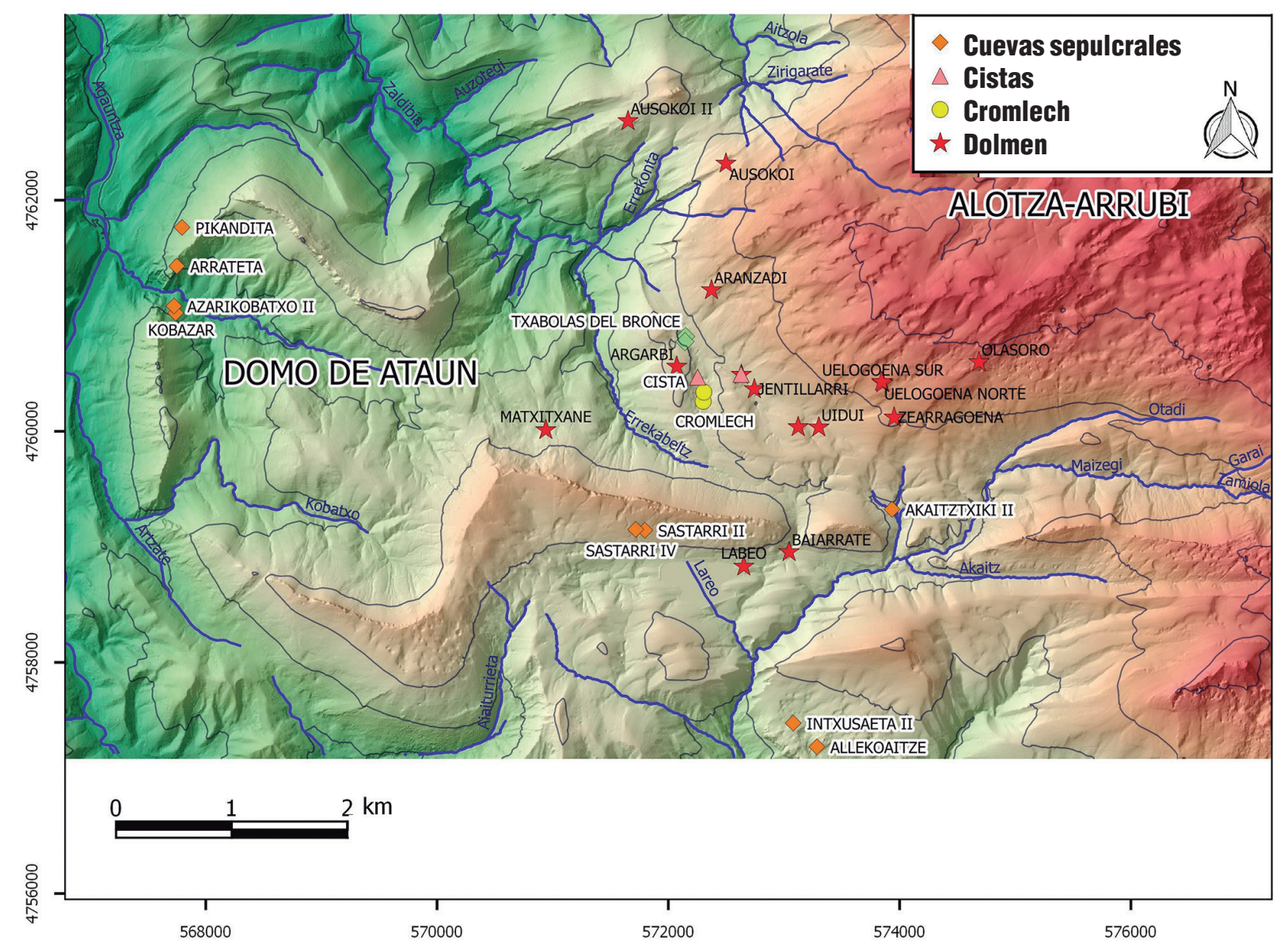

Fig. 1. Yacimientos del entorno de Ondarre en la Sierra de Aralar. / Archaeological sites in Ondarre (Aralar mountain range, Gipuzkoa, Basque Country).

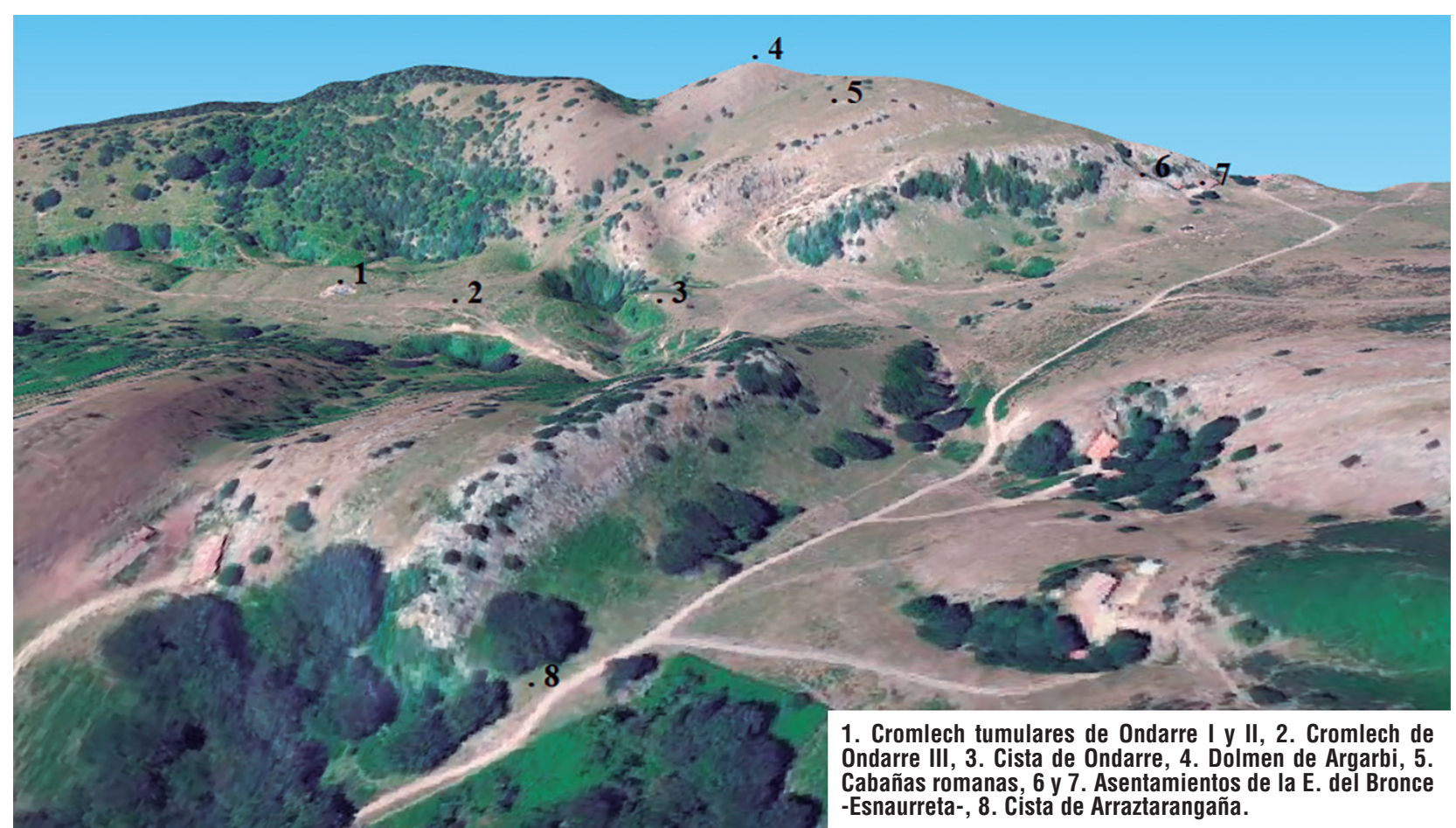

Fig. 2. Localización de los yacimientos más significativos del entorno de Ondarre (Sierra de Aralar). / Location of the most significant sites in the Ondarre area (Aralar). 


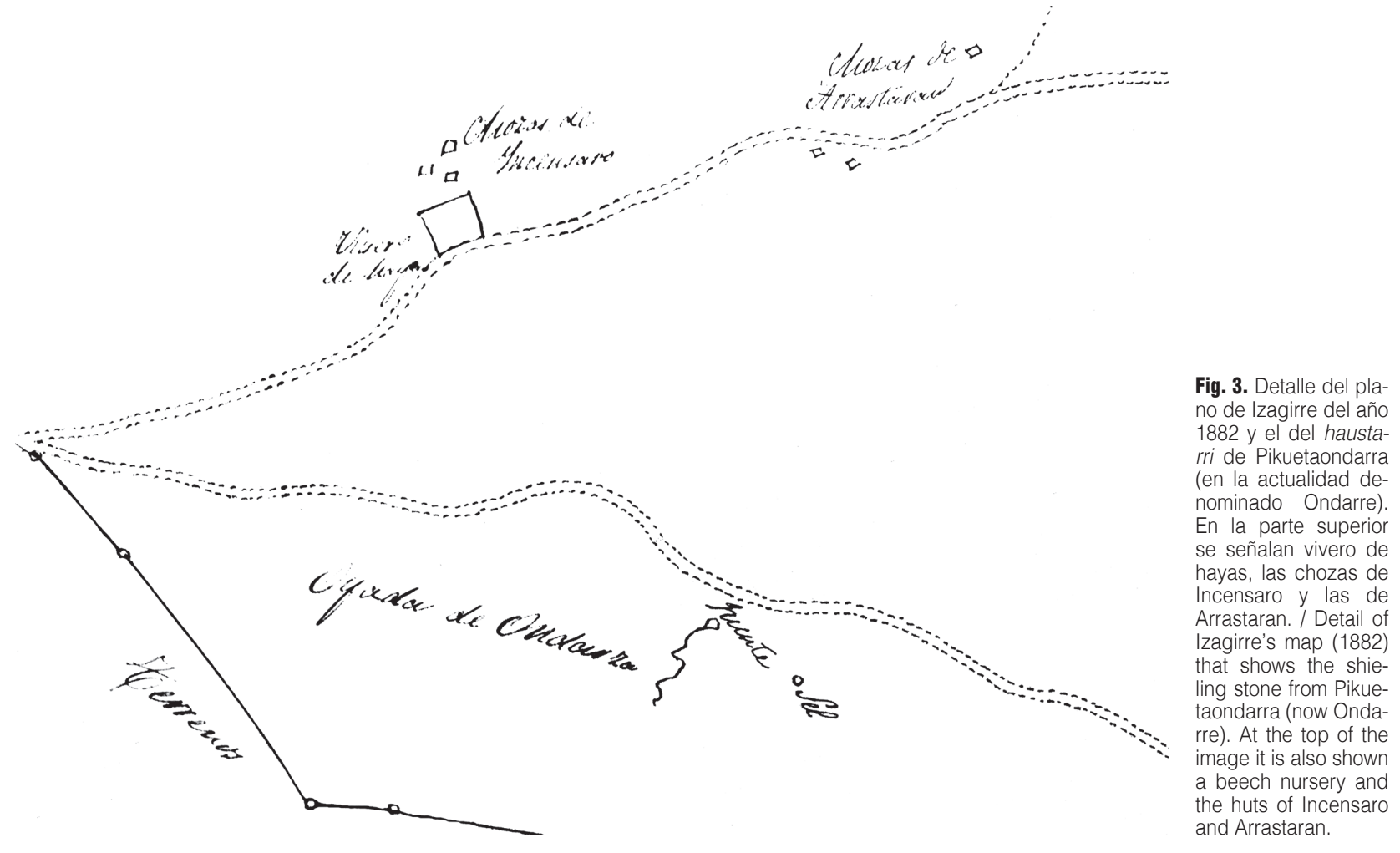

nalmente, a unos $50 \mathrm{~m}$ al sur se localizan los crómlech tumulares de Ondarre I y II.

Existen numerosas referencias documentales de la zona investigada remontándose las más antiguas al siglo XV. Así en 1410, aparece entre los seles del solar de Lazcano (Ficueta hondarra / Fitueta hondarra) junto con el de Ficueta el de suso y, posteriormente, en 1452, se menciona entre los que poseía la Colegiata de Roncesvalles en Enirio-Aralar. En 1717 Roncesvalles vendió sus seles a la villa de Amezketa, hecho que provocó algunos conflictos con la Villa de Ordizia y el Solar de Lazcano, de manera que, en ese contexto, en 1775 se amojonaron los que poseía este último en Aralar. Por otro lado, en el Archivo de la Mancomunidad de Enirio-Aralar, existe un plano realizado en el año 1882 por el agrimensor Martín José Izagirre, donde en la Oyada de Ondarza se representa el mojón cenizal de Ondarre mediante un pequeño círculo con la palabra "sel" al lado, próximo a una fuente situada en una cárcava perpendicular al valle, y junto al camino que se dirige a Navarra (Naparbide).

\section{LAS INTERVENCIONES ARQUEOLÓGICAS}

\subsection{EI cromlech de Ondarre III}

Inicialmente, en el lugar donde se ubica el crómlech, únicamente era visible el haustarri (elemento central de sel o mojón cenizal). En ese punto se practicó en 2009 un sondeo de $1 \mathrm{~m}^{2}$ (Fig. 4) (Agirre et al., 2010).
Los resultados obtenidos dirigieron nuestra atención hacia dos bloques tendidos a unos $50 \mathrm{~m}$, que afloraban parcialmente en el pasto, siendo uno de ellos idéntico al haustarri. La litología y estratigrafía del lugar (principalmente fluvial) evidenciaban un origen antrópico. Los iniciales trabajos realizados permitieron identificar otros bloques que conformarían el crómlech tumular de Ondarre I (Mujika-Alustiza et al., 2016), y más tarde, junto a él, el de Ondarre II. A resultas de estos hechos supusimos que el haustarri indicado pudiera ser el testigo de otro crómlech no visible en la actualidad -Ondarre III-, por lo que se instaló una cuadrícula para proceder a su excavación.

Durante la excavación de Ondarre III se practicó un sondeo central, de aproximadamente 1,66 X 1,33 metros, abarcando el cuadro 8I, y sectores de los cuadros contiguos $7 \mathrm{H}$ (sect. 8, 9), 8H (sect. $7,8,9)$ y $7 \mathrm{I}$ (sect. 2, $3,5,6,8,9$ ). Aquí se profundizaron unos $45 \mathrm{~cm}$ (por debajo aparece ya el relleno fluvio-kárstico del fondo de la depresión), delimitándose -a distintas cotas-, una serie de manchas carbonosas muy tenues y difusas, sobre todo, en 81 (el 55,7\% de los carbones identificados proceden de este cuadro (Tabla 4), y en menor proporción en 7 I (un 34,4\%), así como algunos fragmentos testimoniales en $7 \mathrm{H}$ y $8 \mathrm{H}$. Entre los carbones se han identificado Alnus, Betula, Fagus, Corylus, Quercus y rosáceas. No se han recuperado restos óseos incinerados ni ajuar. La datación mediante C14 de una muestra de carbón (Ondar III.8H.125) arrojó la fecha de 2590 30 BP (Beta 413480, 805-770 Cal BC -2 sigma-). 


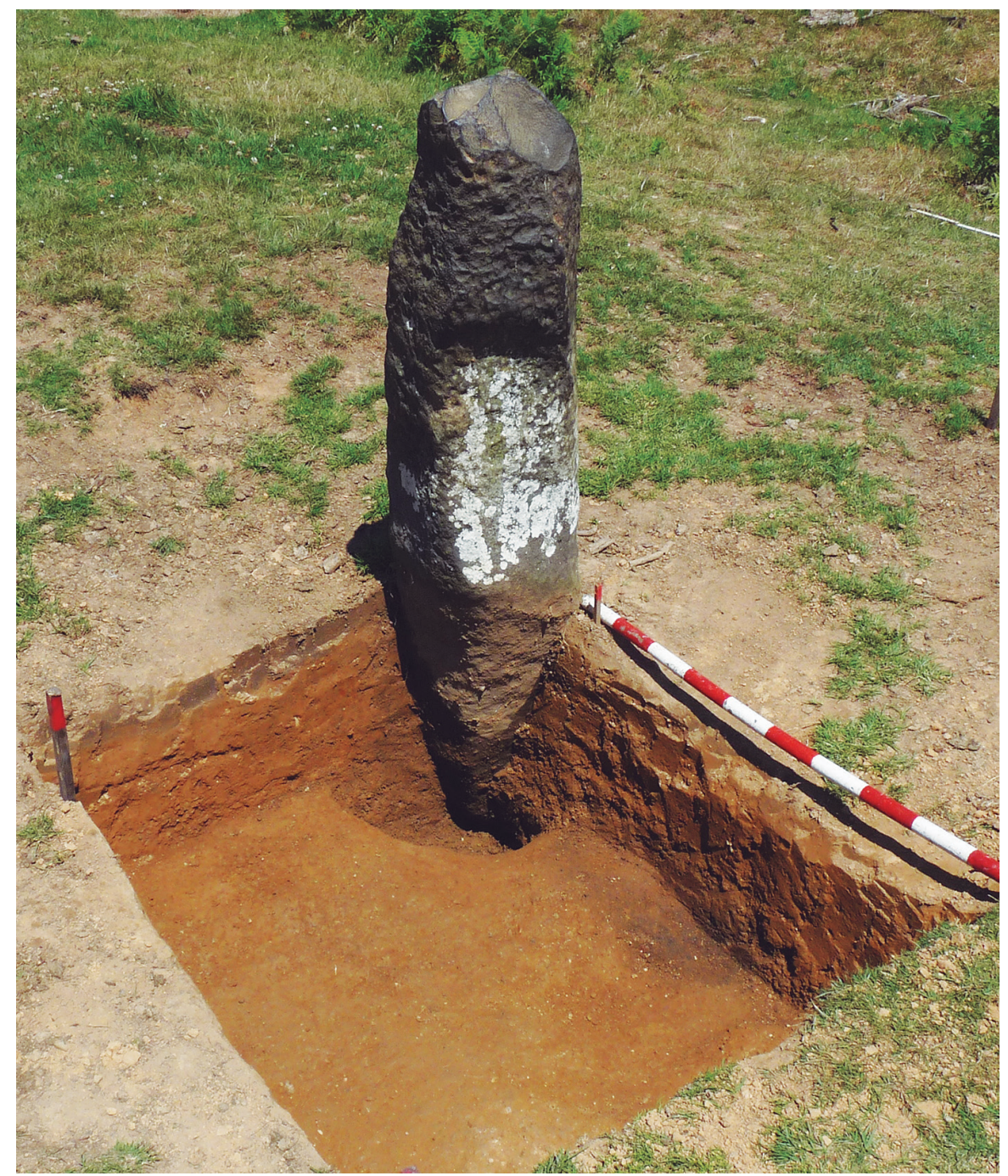

Fig. 4. Sondeo realizado en el haustarri de Ondarre en 2009. A un lado se aprecia una ligera mancha carbonosa datada en el Bronce Final. / The shieling stone from Ondarre excavated in 2009. At a side of the stone there is a charcoal stain dated in the Late Bronze Age.
Por otro lado, durante la intervención tratamos de detectar los testigos ocultos en el subsuelo introduciendo para ello varillas de acero de forma sistemática, siendo el haustarri la referencia fundamental. Este trabajo nos permitió localizar otros tres testigos situados todos ellos al oeste del de referencia. Pudimos así delimitar parcialmente la estructura funeraria original (Fig. 5). En ocasiones, el contacto con otras piedras nos llevó a abrir pequeñas catas, que a veces se ampliaron hasta el metro cuadrado (8D-E y 10F). Las características son las siguientes:

1.- En el cuadro $8 \mathrm{M}$ se localiza el monolito tradicionalmente utilizado como haustarri (Fig. 4). Se trata de un bloque prismático de caliza introducido unos $50 \mathrm{~cm}$ respecto de la superficie actual, situándose los 20 últimos dentro del relleno fluvial. Tiene una altura de $160 \mathrm{~cm}, \mathrm{y}$ una anchura y espesor en la zona media de $20 \times 27 \mathrm{~cm}$, respectivamente. En su extremo superior se observan varios lascados originados por un objeto contundente con el fin de apuntarlo o crear una arista. El sondeo realizado junto a él en 2009 delimitó parcialmente una pe- queña fogata, situada a una profundidad de unos $30 \mathrm{~cm}$ —y a techo del nivel fluvial—, que se introduce en el cuadro contiguo reservado como testigo. La muestra enviada para su datación se fechó en 2821×30 BP (Ua 38687 , 1012-938 Cal BC -2 sigma-, Bronce Final) (Agirre et al., 2010; Lopetegi-Galarraga et al., 2012). En la muestra recogida se identificaron carbones de Corylus, Prunus tipo avium, y Salix/Populus, estas dos últimas especies únicamente representadas en este punto (Tabla 4).

2.- El testigo situado en el extremo sur (cuadro 11K) es un bloque de caliza que había basculado hacia el exterior hasta quedar tendido (Fig. 6). Su extremo exterior estaba a $-30 \mathrm{~cm}$ respecto de la superficie, y el interior a $-35 \mathrm{~cm}$. Sus dimensiones (Alt. X A X E) son: $36 \times 17 \times 16 \mathrm{~cm}$. A $-27 \mathrm{~cm}$ se recogieron algunos carbones, entre los que se identificaron Corylus (1), Fagus (1) y Rosaceae (1). Para confirmar su coetaneidad con otros de la estructura se dató un fragmento de carbón

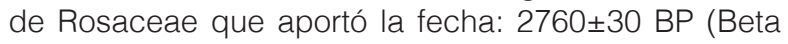
472184, 992-989 y 980-830 Cal BC -2 sigma-). 


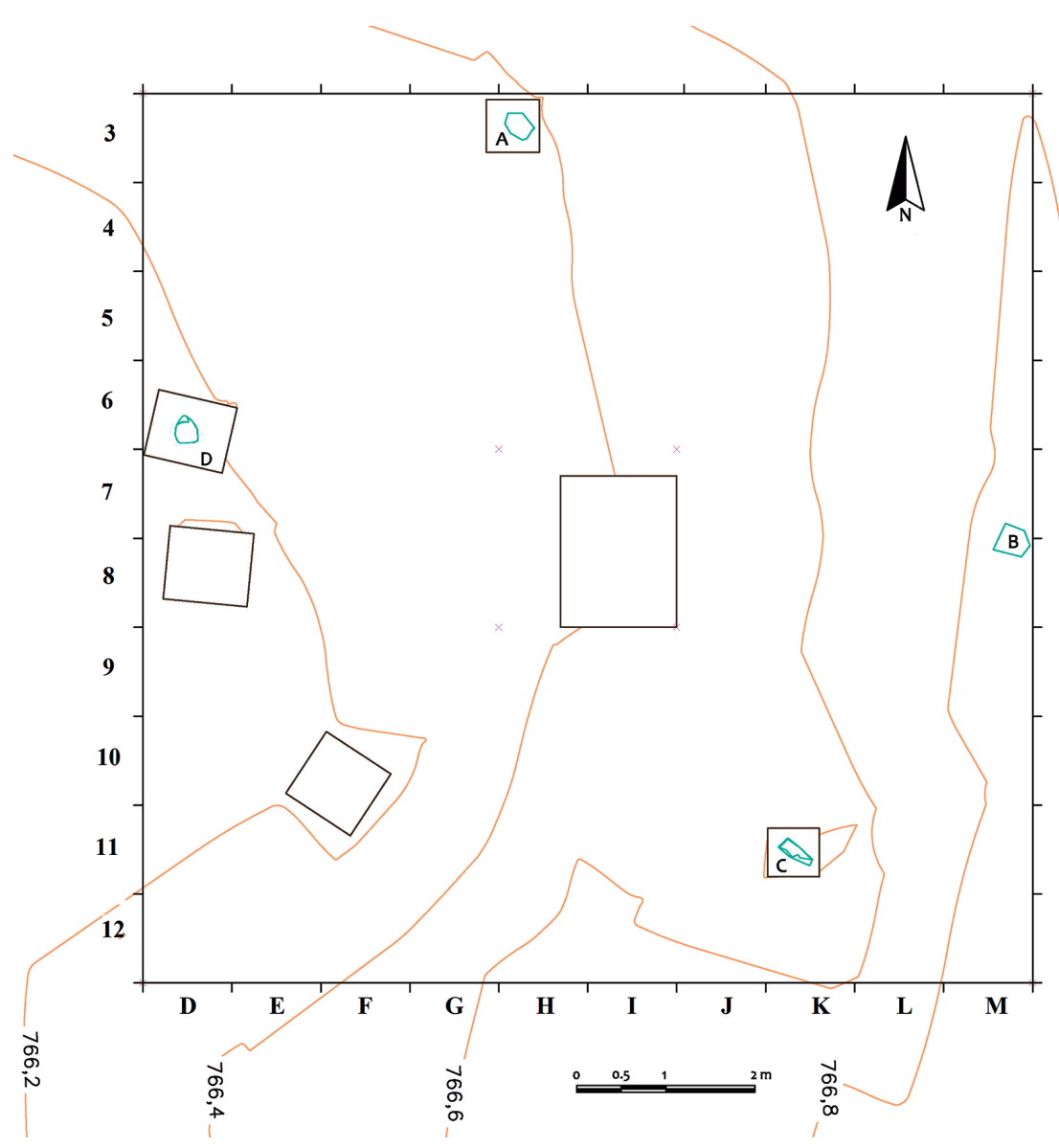

Fig. 5. Planta del baratze de Ondarre III. / Ondarre III stone circle's plan.
3.- En el sector occidental del cromlech, y más concretamente en el cuadro 6D, se descubrió una laja de caliza fétida jurásica, de forma trapezoidal, deficientemente conservada (fracturada en varios trozos, exfoliada, etc.) (Fig. 6). Parte de su base, situada a $-22 \mathrm{~cm}$ de profundidad, estaba semivertical. La altura de la losa superaría ligeramente los $40 \mathrm{~cm}$, ya que no se conserva el extremo superior. Su base mide $38 \mathrm{~cm}$ y su espesor es de $4 \mathrm{~cm}$. En la parte interior del cuadro se alcanzó la profundidad de $-28 \mathrm{~cm}$, mientras que en el exterior tan sólo $-15 \mathrm{~cm}$. Junto al testigo se recuperaron algunos pequeños carbones, identificándose uno de Fagus.

4.- En el lado norte, en el cuadro $3 \mathrm{H}$, hay otro testigo de caliza fosilífera (Fig. 6). Tiene unas dimensiones de 38 (Alt.) X 25 (A) X $10 \mathrm{~cm}$ (E). Su extremo interior estaba a $-29 \mathrm{~cm}$ respecto de la superficie, y el exterior a $-10 \mathrm{~cm}$, por lo que se desplomó en esa dirección. En el sondeo se alcanzaron los $-35 \mathrm{~cm}$ de profundidad. Al pie del testigo se recuperaron algunos carbones, entre los que se identificaron diez de Fagus.

Durante los trabajos de campo no detectamos los restantes testigos del crómlech, pudiendo ser varias las causas: su profunda alteración, su reutilización para la construcción de alguna otra estructura, o no haber excavado una superficie mayor que hubiera permitido detectar indicios de su disolución.

\subsubsection{Los restos materiales}

Los restos industriales recuperados durante el desarrollo de la excavación fueron escasos, y no hay indicios obvios que certifiquen que constituían parte del ritual o ceremonias que se desarrollaron en el lugar. Inmediatamente por debajo del tepe (en 8I), se localizó un raspador sobre lasca de talón plano (de $21,1 \times 23 \times 9,6 \mathrm{~mm}$ ). A medida que se profundizaba, a diferentes cotas, se identificaron pequeñas manchas de carbón, y cinco pequeños fragmentos de lascas de sílex -alguno alterado por el fuego-. Y, finalmente, al fondo del sondeo, en $7 \mathrm{l}$ y $8 \mathrm{l}$, se encontraron tres pequeños fragmentos de cerámica, quizás de alguna urna.

Por otro lado, es destacable también que al pie de tres de los testigos aparecían algunos fragmentos de carbón que no acababan de constituir una mancha bien definida, salvo en el caso de la que se apreciaba junto al haustarri. En cualquier caso la similitud cronológica de todas ellas nos sugiere que se relacionan con un mismo evento, probablemente la construcción del propio crómlech, pudiendo ser considerados como elementos del ritual funerario, aunque por lo observado en otros baratze (por ejemplo Ondarre II) este tipo de depósito no se reproduce de forma sistemática. 

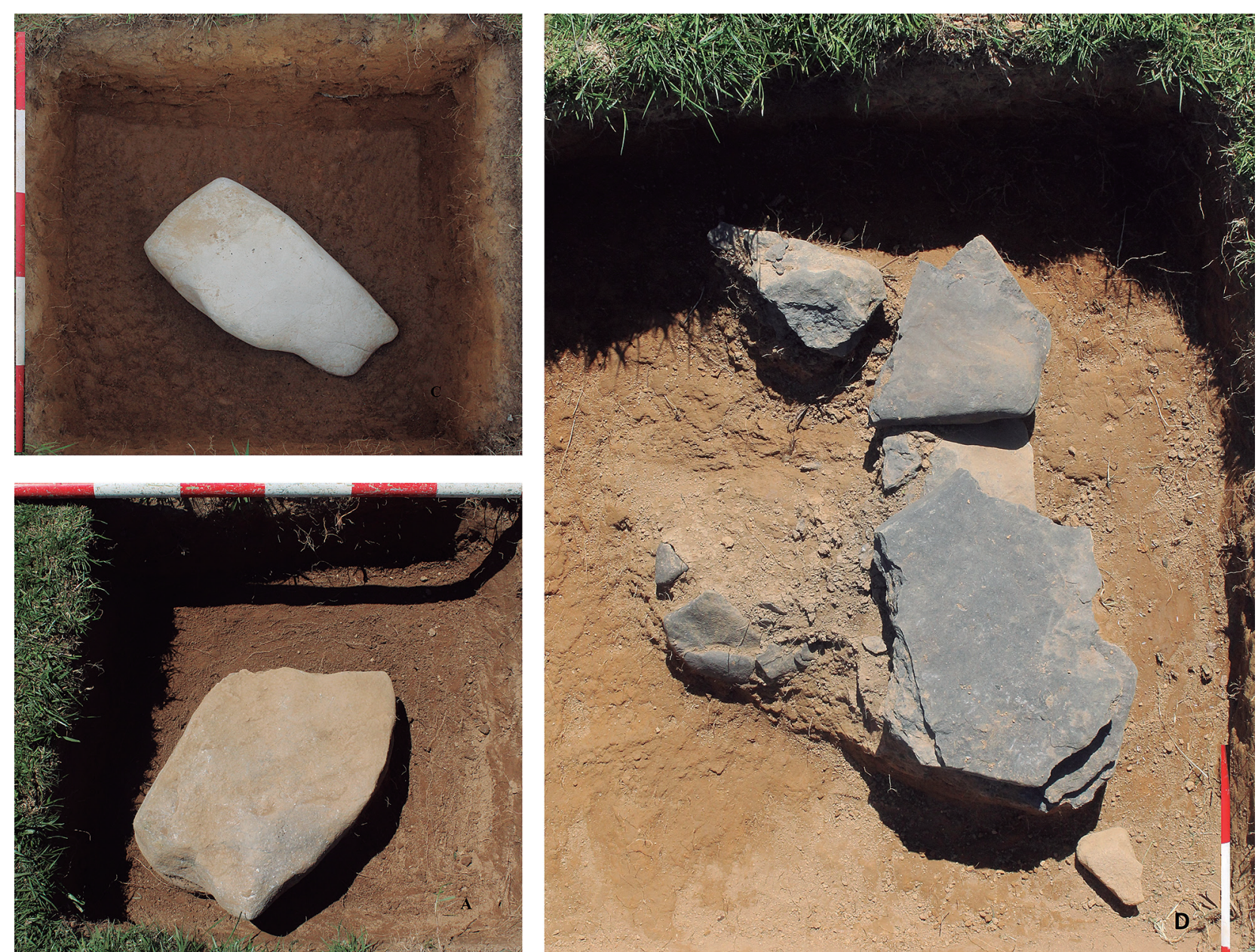

Fig. 6. Testigos del lado oeste, norte y sur. / Standing stones from the west, north and south of the stone circle.

\subsection{El cromlech tumular de Ondarre I}

La primera excavación de un crómlech en la Sierra de Aralar se efectuó en esta estructura funeraria, publicando recientemente la memoria definitiva (Mujika-Alustiza et al., 2016). Se trata de un cromlech tumular de unos 7 metros de diámetro conformado por al menos 35 testigos; de de los que tres son de arenisca y los otros 32 de distintos tipos de calizas.

En la zona central, bajo un túmulo de unos $45 \mathrm{~cm}$ de espesor, se localizó un pequeño depósito de huesos humanos incinerados, pertenecientes, probablemente, a dos individuos juveniles. Sobre estos restos se observaron cuatro losetas de caliza degradadas, que quizás estuvieran inicialmente dispuestas protegiendo dichos restos, así como una densa y amplia mancha carbonosa. Es de destacar que junto al testigo más distinguido se hallaron algunos fragmentos de carbón que han sido datados en 2830 \pm 30 BP (Beta 309100), fecha similar a la obtenida en el núcleo de la estructura: 2740ะ30 BP (Beta 363982). Las incineraciones no iban acompañadas de ajuar alguno. Sólo cerca de uno de los testigos se encontró un canto rodado (percutor, mano de moli- no), una loseta de arenisca fracturada y con retoques periféricos (¿una tapa?) y junto a otro testigo algún trozo de cerámica. En el túmulo se recuperó una punta de flecha, no coetánea del monumento, acarreada en las tierras con las que se construyó, y procedente del entorno más próximo donde se recogieron otras evidencias líticas de cronología probablemente anterior. Su presencia obedecería a la recurrente ocupación del entorno (Mujika-Alustiza et al., 2016: 67).

\subsection{El cromlech tumular de Ondarre II}

Tras confirmar la naturaleza de Ondarre I realizamos una prospección intensiva en su entorno más próximo, ya que en el área de distribución de los crómlechs es habitual la presencia de conjuntos más o menos numerosos. Así se descubrió en 2013 otra nueva estructura a seis metros de distancia, en un punto donde se apreciaba un túmulo muy bajo e irregular, entre otras razones por la acción de topos y jabalíes. Una vez cuadriculada dicha superficie se procedió a realizar un sondeo central y a descubrir los testigos que conforman el crómlech. 


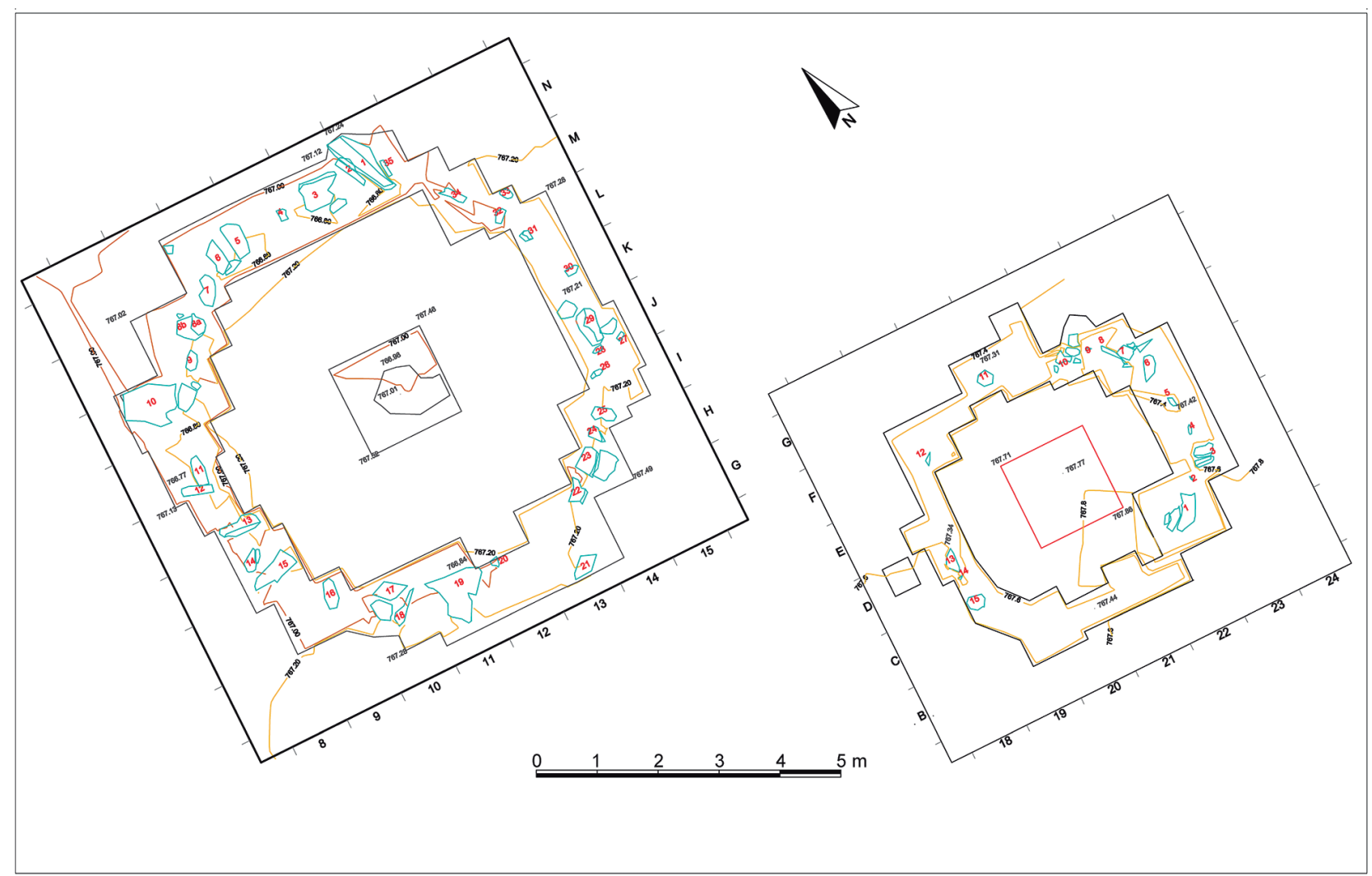

Fig. 7. Planta del crómlech tumular de Ondarre I. / Ondarre I stone circle's plan.

\begin{tabular}{|c|c|c|c|c|}
\hline Labor. $\mathrm{n}^{\circ}$ & Muestra & BP & $13 \mathrm{C} / 12 \mathrm{C}$ & Calibración 2 sigma \\
\hline Ua. 38687 & Ondarre III. Haustarri & $2821 \pm 30$ & $-26,4 \%$ & 1012-938 Cal BC (2962-2888 Cal BP²) \\
\hline Beta 472184 & Ondarre III Lek Heg & $2760 \pm 30$ & $-24.4 \%$ & $\begin{array}{l}\text { 980-830 Cal BC (2929-2779 Cal BP) }(94,9 \%) \\
\text { 992-989 Cal BC (2941-2938 Cal BP) }(0,5 \%)\end{array}$ \\
\hline Beta 413480 & Ondarre III. 8H. 125 & $2590 \pm 30$ & $-25 \%$ & 805-770 Cal BC (2755-2720 Cal BP) \\
\hline Beta 387839 & Ondarre II. 21E & $2770 \pm 30$ & $-27.1 \%$ & 1000-835 Cal BC (2950-2785 Cal BP) \\
\hline Beta 309100 & Ondarre I monolito (13N) & $2830 \pm 30$ & $-23.4 \%$ & 1120-970 Cal BC (3070-2920 Cal BP) \\
\hline Beta 363982 & Ondarre I-12J-5 & $2740 \pm 30$ & $-25.3 \%$ & $\begin{array}{l}\text { 970-960 Cal BC (2920-2910 Cal BP) } \\
\text { 930-820 Cal BC (2880-2780 Cal BP) }\end{array}$ \\
\hline
\end{tabular}

Tabla 1: Dataciones absolutas obtenidas a partir de carbones recuperados en los distintos monumentos de Ondarre. / Radiocarbon dates from the studied archaeological sites in Ondarre.

En la zona central, y más concretamente en los cuadros 20-21/D-E, se realizó un sondeo de 1,5 X 1,5 m, que permitió analizar la estructura. El túmulo está constituido por un sedimento limoarenoso de color marrón claro, casi limpio de clastos de arenisca - excepcionales y de pequeño tamaño-, e igual que el de Ondarre I muy afectado por procesos de bioturbación. Su altura era de unos $40 \mathrm{~cm}$ respecto al nivel de terraza. A medida que se profundizaba afloraron pequeñas y tenues manchas carbonosas, la primera a unos $-25 \mathrm{~cm}$, y a partir de entonces otras similares a distintas cotas. La mayor parte de los carbones proceden de los cuadros 21D y $21 \mathrm{E}$, pero la excavación completa de 20D y 20E, reservados como testigo, podría aportar un número similar de restos. Un fragmento de pericarpio de avellana arrojó la fecha de: $2770 \pm 30$ (Beta 387839; 1000-835 Cal BC -2 sigma-).

${ }^{2}$ CalCurve: CalPal_2007_HULU 


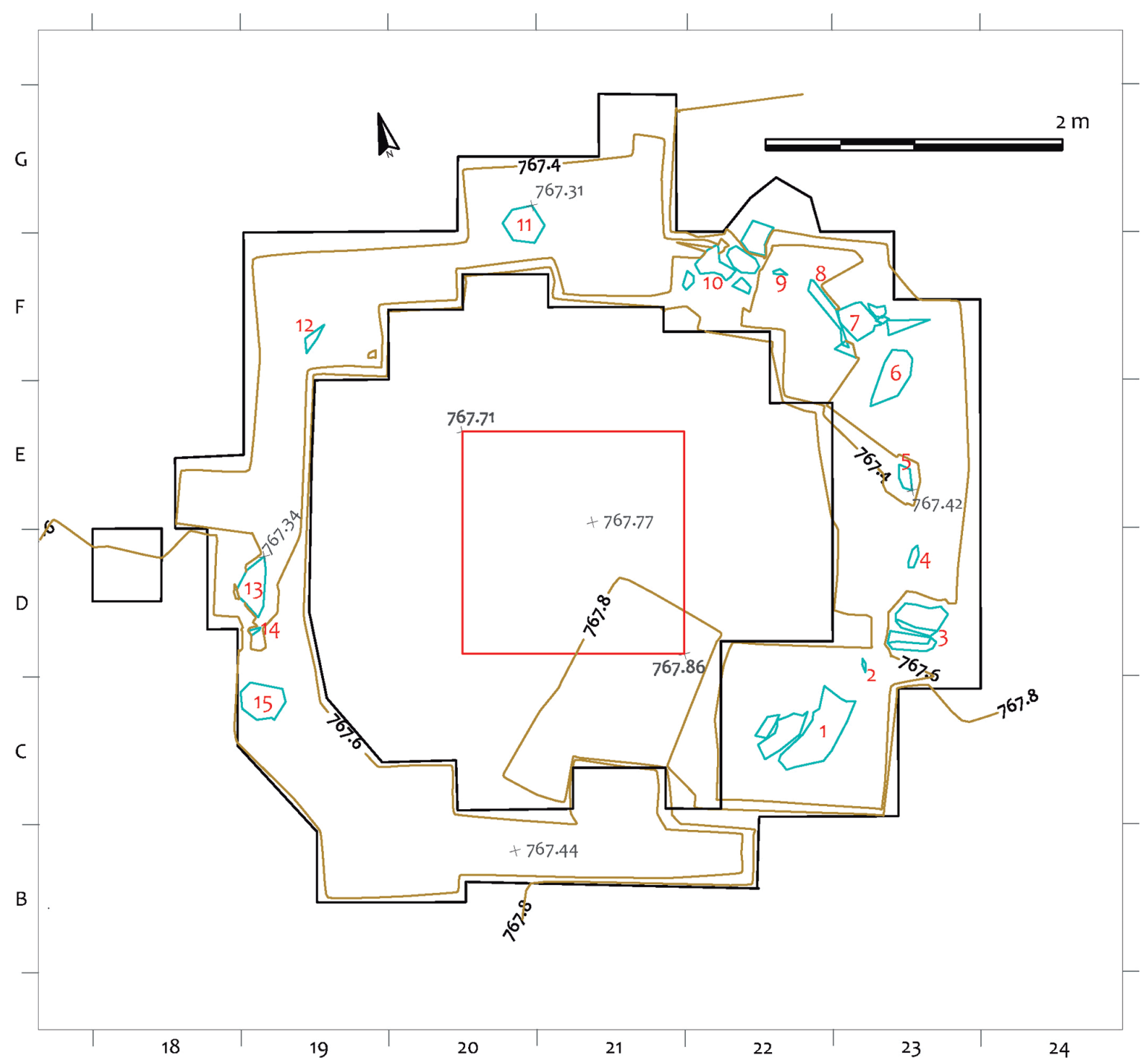

Fig. 8. Planta del crómlech tumular de Ondarre II. / Ondarre II stone circle's plan.
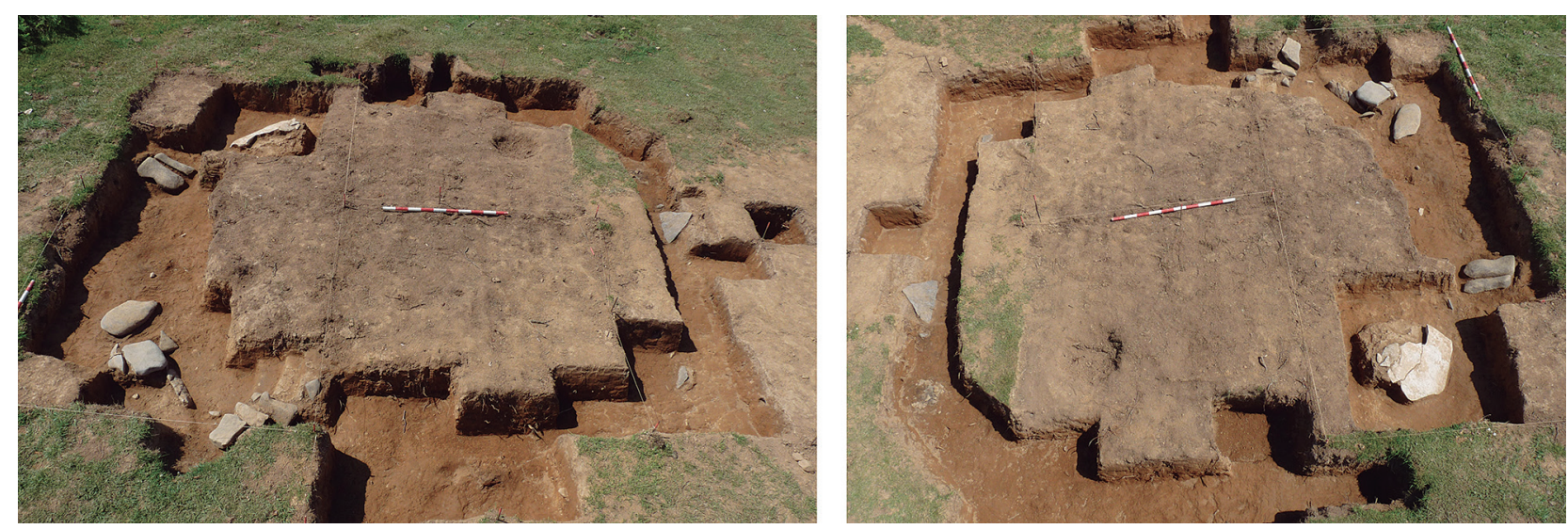

Fig. 9. Crómlech tumular de Ondarre II. / Ondarre II stone circle. 


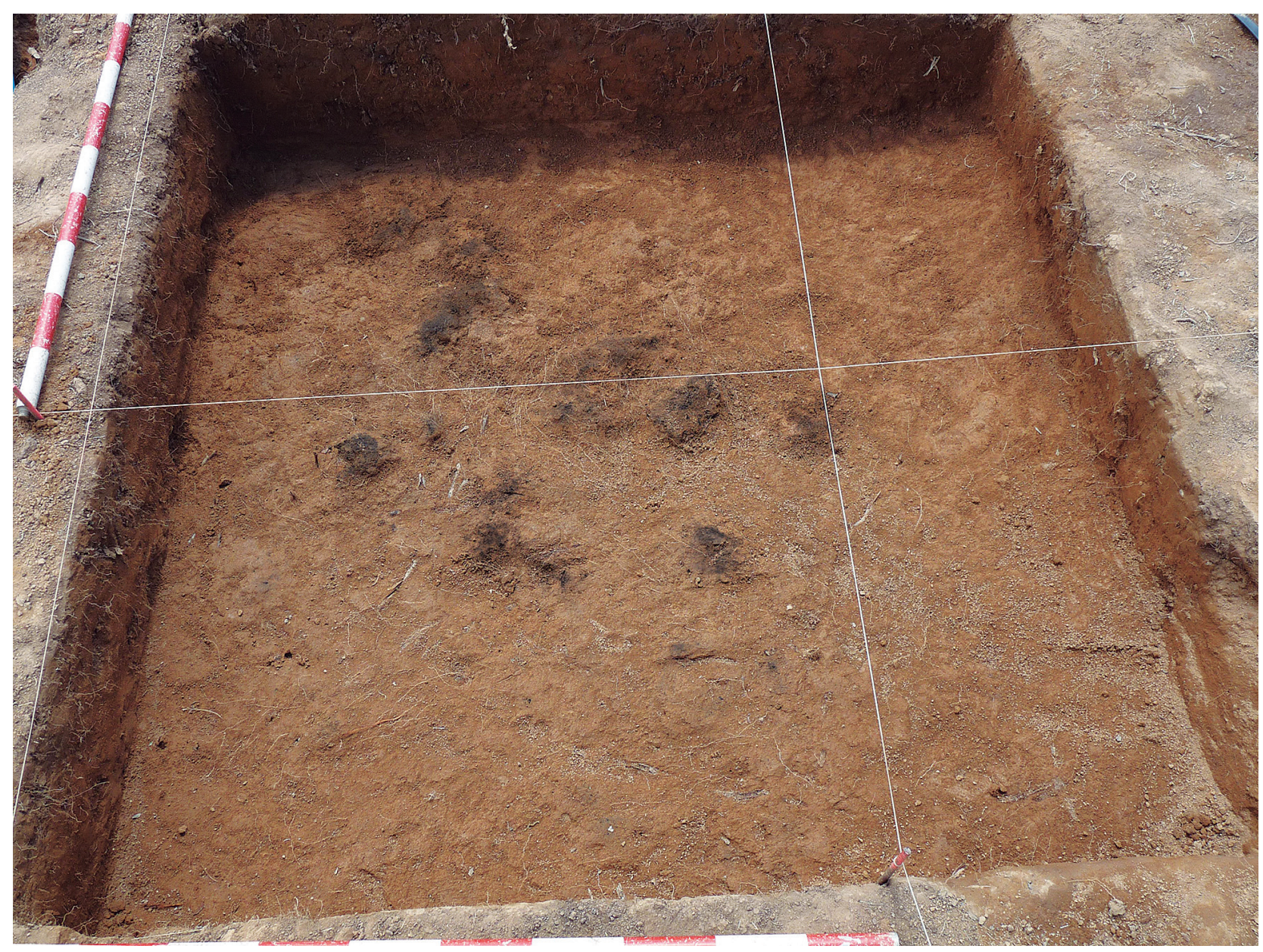

Fig. 10. Manchas carbonosas en el crómlech tumular de Ondarre II. / Charcoal stains in Ondarre II stone circle.

\begin{tabular}{|c|c|c|c|}
\hline $\mathbf{N}^{\circ}$ & Roca & Alt. X L X E cm & Características \\
\hline 1 & Caliza & $\sim 90 \times 60 \times 5$ & Losa fracturada en 3 fragmentos y desplomada hacia el interior. \\
\hline 2 & Caliza & $10 \times 3 \times 2$ & Clasto muy alterado por criptocorrosión. \\
\hline 3 & Caliza & $\begin{array}{l}34 \times 9 \times 6 \\
38 \times 22 \times 6\end{array}$ & $\begin{array}{l}\text { A unos } 27 \mathrm{~cm} \text { hacia el norte existen dos losas paralelas (quizás inicialmente una) } \\
\text { basculadas hacia el exterior. Sus dimensiones son mayores a } 38 \times 31 \times 6 \mathrm{~cm} \text {. }\end{array}$ \\
\hline 4 & Caliza & $16 \times 7 \times 1$ & A $30 \mathrm{~cm}$ del bloque anterior, caído hacia atrás con un ángulo de unos $50^{\circ}$. \\
\hline 5 & Caliza & $10 \times 4 \times 1$ & A $45 \mathrm{~cm}$ del anterior, desplomado hacia el exterior con un ángulo de unos $30^{\circ}$. \\
\hline 6 & Caliza & $44 \times 22 \times 5$ & A $40 \mathrm{~cm}$ del anterior y tendido horizontalmente \\
\hline 7 & Caliza & $40 \times 34 \times 5$ & A $15 \mathrm{~cm}$ de la anterior y fragmentado en 5 trozos. \\
\hline 8 & Caliza & $52 x>12 \times 5$ & Base de una losa de caliza dispuesta casi verticalmente. \\
\hline 9 & Caliza & $5 \times 3$ & Fragmento de clasto situado a $12 \mathrm{~cm}$ del anterior. \\
\hline 10 & Caliza & $\sim 70$ & $\begin{array}{l}\text { Conjunto de cinco fragmentos de caliza. Dos de ellos son pequeños (de } 9 \times 7 \times 4 \\
\text { y } 14 \times 9 \times 4 \mathrm{~cm} \text { ), otros dos están alterados y descontextualizados (de } 23 \times 24 \times 6 \text {, } \\
\text { y } 26 \times 16 \times 6 \mathrm{~cm} \text { ). Finalmente, el quinto bloque (de } 27 \times 26 \times 8 \mathrm{~cm} \text { ) está vertical, } \\
\text { con cierta inclinación hacia el interior. }\end{array}$ \\
\hline 11 & Caliza & & Mancha dudosa \\
\hline 12 & Caliza & $30 \times 25 \times 2$ & Losa en posición casi vertical $\left(70^{\circ}\right)$. \\
\hline 13 & Caliza & $45 \times 40 \times 3$ & Losa de caliza prácticamente vertical $\left(70^{\circ}\right)$ y basculada hacia el exterior. \\
\hline 14 & Caliza & $8 \times 5 \times 1$ & Muy alterada \\
\hline 15 & Arenisca & $30 \times 25 \times 4$ & Muy alterada \\
\hline
\end{tabular}

Tabla 2: Características de los testigos del cromlech Ondarre II. / Characteristic of the standing stones from Ondarre II stone circle. 
La labor de descubrir los testigos que configuraban el crómlech fue laboriosa debido a su deficiente estado de conservación y a la desaparición de muchos de ellos. Tras la prospección y realización de catas de tanteo, afloraron varios bloques, fracturados y alterados, en el arco oriental del crómlech, concretamente en las bandas 22 y 23, mientras que la excavación de los restantes lados, apenas permitió ampliar su número (Arévalo et al., 2015; Edeso et al., 2014). Finalizada la excavación se documentaron 15 testigos (14 de caliza y 1 de arenisca) muy fragmentados y alterados, siendo sus dimensiones más discretas que las observadas en el monumento contiguo. Los bloques de caliza han sido afectados por procesos de disolución bajo suelo, concretamente por criptocorrosión diferencial, y son el resultado de aguas cargadas de ácido carbónico y ácidos orgánicos (acético, fórmico, tánico, húmico...) que atacan a la roca dentro del suelo disolviéndola. El origen de estos ácidos está relacionado con la descomposición de la materia orgánica (natural o incrementada por la actividad ganadera) y con la respiración de las plantas. Este proceso es mayor si el agua es fría (aguas de fusión de nieve o hielo), pudiendo disolver una roca en un intervalo de tiempo relativamente corto.

\subsubsection{Los restos materiales}

Durante la excavación no se detectaron indicios que nos indicasen la deposición de restos humanos incinerados en la zona central, ni de elementos de ajuar. Se han hallado únicamente tres objetos de sílex, probablemente evidencias de alguna efímera ocupación de cronología incierta. Las características de dichas piezas son las siguientes:

- En 21D, un fragmento medial de lasca de 11,2 X 10,1 X 3,1 mm. Sílex evaporítico.

- En 21D, un raspador carenado, talón plano, y de 24 X 23 X 11,4 mm. Sílex del Flysch.
- En 19E, un raspador de 21,5 X 32,5 X 12,5 mm. Sílex de Urbasa.

Con el fin de verificar o descartar la existencia de algún asentamiento en las inmediaciones de la estructura se practicó una cata en el exterior del túmulo, donde se recuperaron una raedera denticulada lateral convexa sobre una lasca laminar de decorticado de talón plano (de 54,1 X 30,2 X 14,5 mm); un fragmento proximal de lasca astillada (de $27 \times 26,5 \times 6,2 \mathrm{~mm}$ ) y un fragmento medial de lámina de sección trapezoidal con huellas de uso en una de las aristas (de $30 \mathrm{X} 17 \mathrm{X}$ $3,7 \mathrm{~mm})$.

\section{LOS MACRORRESTOS VEGETALES}

Tras los trabajos de campo que se vienen realizando en los últimos años en la zona de Ondarre (Mujika-Alustiza et al., 2016) se han estudiado los macrorrestos vegetales recuperados en los cromlech Ondarre II y III. Esta investigación de los restos antracológicos se ha realizado en los Laboratorios de Arqueobiología del Instituto de Historia en el Centro Ciencias Humanas y Sociales del Consejo Superior de Investigaciones Científicas, utilizándose para ello un microscopio de luz incidente Leica DM 4000M (50x/100x/200x/500x) a través de la comparación anatómica de sus diferentes secciones, con los atlas de anatomía de la madera del laboratorio (Schweingruber, 1990; Hather, 2000; Vernet et al. 2001).

\subsection{Ondarre II}

En este enclave se han recogido un total de 14 muestras cuyas características se recogen en la tabla adjunta, ordenadas por cuadros (20E, 20D, 21D y 21E) y profundidades, no habiéndose hallado carbones junto a los testigos excavados. Se han estudiado un total de 268 carbones ( $>2 \mathrm{~mm}$ ) de los cuales 8 han resultado no identificables (Tabla 3 ).

\begin{tabular}{|c|c|c|c|c|c|c|c|c|c|c|c|c|c|c|}
\hline Cuad & $z$ & Alnus & Betula & Betula/Alnus & Corylus & Fagus & Fraxinus & Ilex aqu. & Pomoid & $Q s Q$ & Rosac & Salix/ Populus & No id. & Total \\
\hline $20 \mathrm{E}$ & 33-37 & & 2 & & 1 & 3 & & & 3 & & & & & 9 \\
\hline $20 \mathrm{E}$ & $37-45$ & & 3 & & 5 & 2 & 1 & & 5 & & & & & 16 \\
\hline $20 \mathrm{E}$ & 49 & & 2 & & & & & & & & & & & 2 \\
\hline 20D & $36-38$ & & & & & 2 & & & 7 & & & & & 9 \\
\hline 20D & $38-46$ & & 1 & & & 6 & & & & & 6 & & & 13 \\
\hline 21D & $27-32$ & & & 14 & 2 & 3 & & & 9 & 1 & & & & 29 \\
\hline 21D & $32-38$ & & 7 & & & 5 & 2 & & 14 & & & & 3 & 31 \\
\hline 21D & $38-51$ & 8 & 5 & & 1 & 5 & 1 & & 15 & & 7 & & 2 & 44 \\
\hline $21 E$ & $28-37$ & & 2 & & 2 & 6 & & & 21 & 1 & & & & 32 \\
\hline $21 E$ & $37-40$ & & 3 & & 2 & 5 & 1 & & 17 & 1 & 4 & 3 & & 36 \\
\hline \multirow[t]{2}{*}{$21 E$} & $40-49$ & & 5 & & 7 & 13 & 2 & 1 & 2 & & 3 & & 2 & 35 \\
\hline & 38 & & 4 & & 1 & 3 & & & & & 3 & & 1 & 12 \\
\hline \multicolumn{2}{|c|}{ TOTAL } & 8 & 34 & 14 & 21 & 53 & 7 & 1 & 93 & 3 & 23 & 3 & 8 & 268 \\
\hline
\end{tabular}

Tabla 3: Resultados absolutos de los macrorrestos vegetales recuperados en Ondarre II. / Total charred plant remains retrieved from Ondarre II. 
En Ondarre II la madera mejor representada es la de las rosáceas (> 44,5\%), entre las que destacan las de tipo pomoidea, seguido de la de haya $(20,4 \%)$ y abedul (ca. 13\%), y en menor medida el avellano (> 8\%). El resto (aliso, Salix/Populus, fresno, acebo y Quercus caducifolio) tienen una representación mucho menor (Tabla 5; Fig. 11)

\subsection{Ondarre III}

De los tres cromlech es el que ha aportado el menor número de macrorrestos. Se han estudiado un total de 99 fragmentos de madera carbonizada procedentes tanto de las diferentes capas del sondeo central (61) como de los testigos (38), perteneciendo todos ellos al mismo evento por lo que se interpretan de forma conjunta (Tabla 4). De estos, 96 han resultado identificables. Los taxones identificados son similares (excepción hecha de la ausencia de Fraxinus) a los observados en Ondarre II y I (Mujika-Alustiza et al., 2016), destacando por su abundancia Fagus sylvatica (haya), seguida de rosáceas y de Quercus caducifolio. Otros taxones presentes son alisos, sauces o abedules, y así como avellano (Tablas 4 y 5, Fig. 11).

\begin{tabular}{|c|c|c|c|c|c|c|c|c|c|c|c|c|c|}
\hline Cuadro & $z$ & Alnus & Betula & $\begin{array}{c}\text { cf Betula / } \\
\text { Alnus }\end{array}$ & Corylus & Fagus & cf Fagus & $\begin{array}{l}\text { Prunus tp. } \\
\text { avium }\end{array}$ & $Q s Q$ & Rosac & $\begin{array}{c}\text { Salix/ } \\
\text { Populus }\end{array}$ & No id. & Total \\
\hline $7 \mathrm{H}$ & 119 & 1 & & & & & & & & 1 & & & 2 \\
\hline 71 & $108 / 112$ & & & & & 1 & & & 2 & 13 & & & 16 \\
\hline 71 & 127 & & & & & 4 & & & & & & 1 & 5 \\
\hline $8 \mathrm{H}$ & 115 & & 1 & & & & & & & & & & 1 \\
\hline $8 \mathrm{H}$ & 125 & & & & 1 & & & & 1 & & & 1 & 3 \\
\hline 81 & $112 / 114$ & & 2 & & 2 & 7 & & & 4 & & & 1 & 16 \\
\hline 81 & $120 / 127$ & & & & 3 & & & & 7 & 4 & & & 14 \\
\hline 81 & $130 / 136$ & & & 1 & & & & & 3 & & & & 4 \\
\hline \multicolumn{2}{|c|}{ Total } & 1 & 3 & 1 & 6 & 12 & & & 17 & 18 & & 3 & 61 \\
\hline 6D & 20 & & & & & & 1 & & & & & & 1 \\
\hline $11 \mathrm{~K}$ & 27 & & & & 1 & 1 & & & & 1 & & & 3 \\
\hline $3 \mathrm{H}$ & $19 / 26$ & & & & & 13 & & & & & & & 13 \\
\hline \multicolumn{2}{|c|}{$8 M(2009)$} & & & & 5 & & & 10 & & & 6 & & 21 \\
\hline \multicolumn{2}{|c|}{ Total } & & & & 6 & 14 & 1 & 10 & & 1 & 6 & & 38 \\
\hline \multicolumn{2}{|c|}{ TOTAL } & 1 & 3 & 1 & 12 & 26 & 1 & 10 & 17 & 19 & 6 & 3 & 99 \\
\hline
\end{tabular}

Tabla 4: Resultados absolutos de Ondarre III. / Total charred plant remains retrieved from Ondarre III.

\begin{tabular}{|l|c|c|c|c|c|c|}
\cline { 2 - 8 } \multicolumn{1}{c|}{} & \multicolumn{2}{c|}{ ONDARRE I } & \multicolumn{2}{c|}{ ONDARRE II } & \multicolumn{2}{c|}{ ONDARRE III } \\
\hline Acer sp. & 2 & $0,1 \%$ & & & & \\
\hline Alnus sp. & 9 & $0,3 \%$ & 8 & $3,1 \%$ & 1 & $1,0 \%$ \\
\hline Betula sp. & & & 34 & $13,1 \%$ & 3 & $3,1 \%$ \\
\hline Betula/AInus & & & 14 & $5,4 \%$ & 1 & $1,0 \%$ \\
\hline Corylus avellana & 50 & $1,7 \%$ & 21 & $8,1 \%$ & 12 & $12,4 \%$ \\
\hline Ericaceae & 5 & $0,2 \%$ & & & & \\
\hline Fagus sylvatica & 1089 & $37,5 \%$ & 53 & $20,4 \%$ & 27 & $28,1 \%$ \\
\hline Fraxinus sp. & 1744 & $60,1 \%$ & 7 & $2,7 \%$ & & \\
\hline Ilex aquifolium & & & 1 & $0,4 \%$ & & \\
\hline Pomoideae & & & 93 & $35,8 \%$ & & \\
\hline Prunus tp. avium & & & & & 10 & $10,4 \%$ \\
\hline Quercus caducifolio & 3 & $0,1 \%$ & 3 & $1,2 \%$ & 17 & $19,8 \%$ \\
\hline Rosaceae & & & 23 & $8,8 \%$ & 19 & $17,7 \%$ \\
\hline Salix/Populus & & & 3 & $1,2 \%$ & 6 & $6,2 \%$ \\
\hline TOTAL & \multicolumn{2}{|c|}{2902} & \multicolumn{2}{|c|}{$\mathbf{2 6 0}$} & \multicolumn{2}{|c|}{$\mathbf{9 6}$} \\
\hline
\end{tabular}

Tabla 5: Resultados absolutos y porcentuales de carbones identificados de Ondarre I, II y III. / Total charred plant remains and percentage retrieved from Ondarre I, II and III.

\section{EL ESTUDIO PALINOLÓGICO}

El estudio palinológico de las estructuras de Ondarre II y Ondarre III se ha realizado sobre un total de 5 muestras (2 y 3 respectivamente), recuperadas durante el desarrollo de la excavación arqueológica. Estas han sido sometidas a un tratamiento químico convencional en las instalaciones del Grupo de Investigación Arqueobiología del CSIC (Instituto de Historia, Centro de Ciencias Humanas y Sociales, Madrid), siguiendo las pautas del denominado método clásico (Girard y Renault-Miskovsky, 1969; Burjachs et al., 2003) con el fin de aislar los microfósiles polínicos y no polínicos para su posterior identificación. Una vez lavado, el sedimento, es sometido a un primer ataque con $\mathrm{HCl}$ para la eliminación de los carbonatos. Tras su neutralización, mediante sucesivos lavados con agua destilada y centrifugados, se añade $\mathrm{NaOH}$ para la eliminación de la materia orgánica. Se recupera el contenido polínico mediante un licor denso como el Thoulet (Goeury y Beaulieu, 1979), que permite separar los microfósiles polínicos y no polínicos del resto por diferencia den- 
simétrica con ayuda de un desintegrador ultrasónico. Tras un filtrado, utilizando filtros de fibra de vidrio, éstos se deshacen usando HF que además permite eliminar los restos de silicatos. La porción final del sedimento se conserva en gelatina de glicerina para su posterior montaje y lectura al microscopio óptico. Para la identificación de los microfósiles polínicos y no polínicos se ha utilizado un microscopio óptico (modelo Nikon Eclipse 50i), con objetivos de 40X, 60X y 100X, este último con aceite de inmersión.

El recuento de pólenes, esporas y microfósiles no polínicos arroja resultados desiguales. Mientras que en Ondarre II tan solo una de las muestras ha resultado positiva desde el punto de vista palinológico, en el caso de Ondarre III, de las tres analizadas solo dos de ellas contenían la cantidad mínima de palinomorfos necesarios, establecido en 250-300 pólenes, para poder ser considerada como un indicador de la vegetación circundante (muestras A y B) (Fig. 11).

En conjunto, ambas estructuras presentan un espectro vegetal muy similar, tanto entre sí como con la cercana estructura de Ondarre I (Mujika-Alustiza et al., 2016), por lo que se ha incluido en el mismo histograma palinológico. Ello no es extraño teniendo en cuenta la cercanía de las tres estructuras y su adscripción cronológica, ciertamente similar. El paisaje circundante estaba conformado en gran parte por masas forestales (valores cercanos al 70\%) en las que los caducifolios son dominantes. Entre ellos, los avellanos son los mejor representados, junto con robledales. Otros caducifolios con cierta presencia son alisos, fresnos, sauces, abedules, hayas y tilos, con valores reducidos $(<3 \%)$, todos ellos presentes en el espectro antracológico. A pesar de la presencia de masas arbóreas, se evidencia cierta apertura paisajística de indudable origen antrópico. La presencia de vegetación antrópica nitrófila (Dipsacus fullonum tipo, Aster tipo, Cardueae, Cichorioideae, Convolvulus arvensis tipo) y antropozoógena
(Chenopodiaceae, Plantago sp., Urtica dioica tipo), junto con praderas de gramíneas indican claramente la influencia humana en la configuración paisajística de este entorno. Sin embargo, no se detectan evidencias directas del desarrollo de prácticas económicas productoras a escala local, ya que no se han identificado ni especies vegetales cultivadas ni hongos de ecología coprófila, claros indicadores de la presencia de ganado in situ (Fig. 11). Ello sugiere la existencia de un ambiente templado y húmedo, propicio para el desarrollo de los bosques mesófilos, que también tienen reflejo en el estudio antracológico señalado en este mismo trabajo.

\section{DISCUSIÓN}

\subsection{La arquitectura y materia prima}

Los monumentos funerarios investigados están construidos con distintos tipos de rocas calizas, procedentes de los estratos situados en las laderas que conforman la depresión fluvio-kárstica. Sólo ocasionalmente se han utilizado bloques de arenisca (dos en Ondarre I y uno en Ondarre II), cuyo origen estaría en la ladera norte o este. Tanto el número original de bloques como sus características morfológicas y morfométricas se han modificado sustancialmente. Cierto número ha podido ser reutilizado, mientras que el resto ha sido erosionado fragmentándose en varias partes y disolviéndose total o parcialmente como consecuencia de los procesos de karstificación.

El estado de conservación de estos sencillos monumentos y la posición actual de sus elementos (tendidos y cubiertos por el sedimento) dificulta su detección, tanto en este caso como en otros (Edeso-Fito et al., 2016). En los últimos años se han realizado trabajos para localizar necrópolis del Bronce Final y Edad del Hierro en Gipuzkoa, pero por su dificultad han dado pocos resultados (San Jose y Peñalver, 2009).

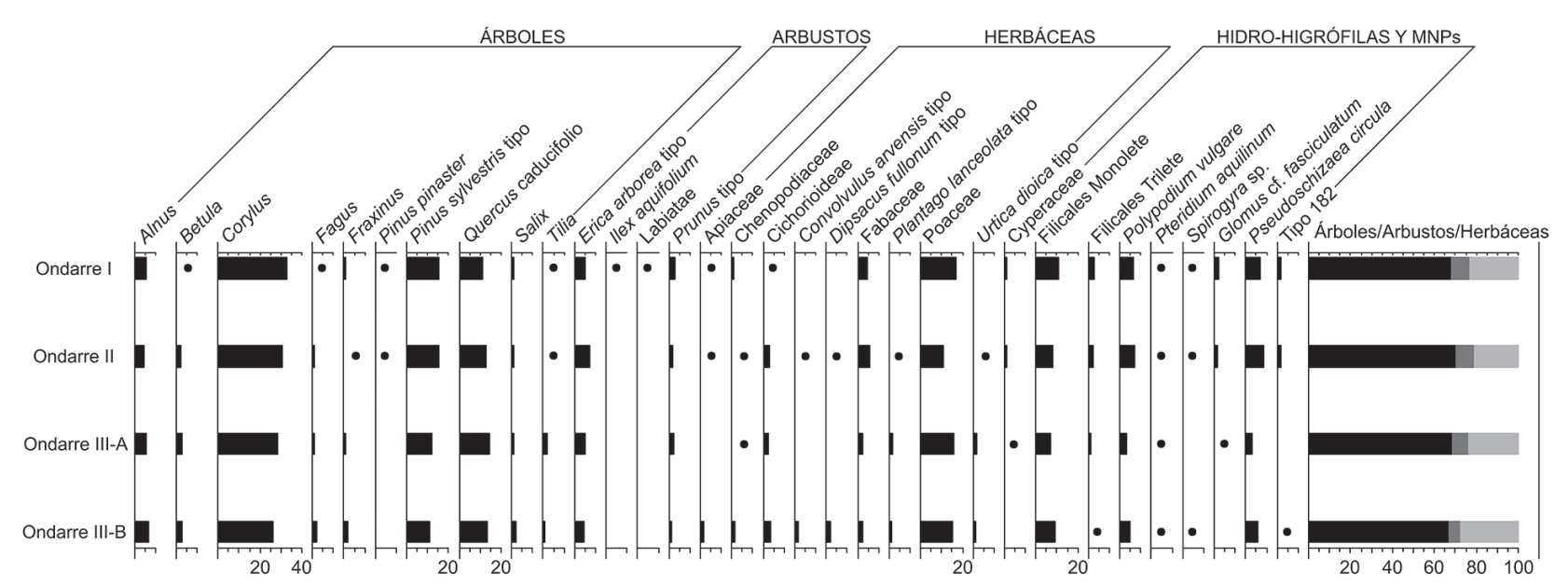

Fig. 11. Histograma palinológico de los crómlech de Ondarre. / Histogram from the stone circles of Ondarre. 
Los bloques de caliza han sido afectados por criptocorrosión diferencial. La acción de estos procesos geoquímicos, y reutilizaciones, explican la ausencia de muchos testigos originales. Las dimensiones de los hallados son discretas y se han reducido también por fragmentación y disolución. Entre todos ellos destacan dos bloques prismáticos alargados (> $120 \mathrm{~cm}$ ) por seleccionarse el mismo tipo de caliza. La mayoría de los bloques son planos, y tienen formato de laja más o menos corta (Ondarre I -testigos $n^{\circ} 3,10,19$, etc.—; Ondarre II testigo $\mathrm{n}^{\circ} 1$ - y Ondarre III — testigo occidental-).

El diámetro de estas estructuras varía entre los 4,5 $\mathrm{m}$ de Ondarre II y los $9 \mathrm{~m}$ de Ondarre III, siendo de $7 \mathrm{~m}$ el de Ondarre I. Dos de ellos (I y II) están provistos de un túmulo de tierra de unos $40-50 \mathrm{~cm}$ de altura, donde a distintas cotas se han observado pequeñas manchas carbonosas, más abundantes en las más profundas. Destaca Ondarre I que conservaba un amplio y denso lentejón de carbones.

\subsection{El ritual}

Los sondeos practicados en Ondarre han permitido corroborar lo señalado con anterioridad: la inexistencia de restos óseos incinerados en unos y la de otros que los conservaban en cantidades variables. Así, en el País Vasco tenemos que Ondarre I aportó $150 \mathrm{~g}$, Millagate V $(2730 \pm 60 \mathrm{BP})$ y Errozate II $(2680 \pm 100 \mathrm{BP})$ unas pocas esquirlas, el crómlech grande de Oianleku $150 \mathrm{~g}$ y

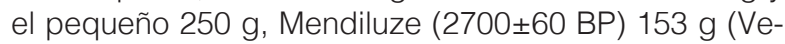
gas, 2001; 2002), mientras que en el "túmulo-cromlech" de Millagate IV (2120 \pm 60 BP) eran 1500 g (Blot, 1977; 1988; 1991; 2013; Blot y Raballand, 1995; Peñalver, 2005). Sin embargo, consideramos este último sepulcro como un cofre con túmulo y peristalito o crómlech. Las pequeñas dimensiones de su cámara $(105 \times 50 \mathrm{~cm})$ y el hecho de que los restos óseos incinerados, confinados en un espacio de $40 \times 20 \mathrm{~cm}$, aparezcan a techo del relleno (pegados a la cubierta), nos llevan a proponer que ésta es una reutilización de dicho espacio cuando ya estaba colmatada. Volviendo a los crómlech de Aralar había manchas carbonosas más o menos importantes en la zona central, abundantes en Ondarre I, pero escasas en Ondarre II y III. Además, tienen en común que apenas hay claros elementos de ajuar u ofrendas, salvo los tres fragmentos cerámicos (¿urna?) de Ondarre III.

También se han recogido carbones a los pies de algunos testigos (en uno de Ondarre I, en los cuatro de Ondarre III, pero en ninguno de Ondarre II), y las fechas aportadas por tres de ellos indican que son coetáneos de la construcción del baratze y de su depósito central. Esto, quizás, podría hacerse extensivo a otros restos arqueológicos de Ondarre I (canto rodado - ¿mano de molino?-, fragmentos cerámicos, etc.). Sólo la concentración detectada al pie del testigo del crómlech Ondarre III, reutilizado como haustarri, permite sospechar que se encendió una fogata no estructurada. Parte de los carbones de la zona central de Ondarre I tam- bién podrían proceder de otra hoguera ritual prendida ahí. La conservación e identificación de las ciperáceas sería bastante improbable si hubiera habido una manipulación importante.

Las fechas, en torno al $2750 \mathrm{BP}$, indican que la incineración estaba bastante extendida en el Pirineo occidental y que la cantidad de restos cremados depositada es mínima, una muestra simbólica, excepto en Millagate IV (¿por una evolución del criterio de selección?). Parece que su selección no obedece a un criterio muy normativizado a juzgar por su variabilidad. Sin embargo, es probable que la parte inmaterial del ritual, que desconocemos, fuera más estricta.

En otro tipo de necrópolis protohistóricas la presencia de restos cremados es también muy variable. Por ejemplo, en la de Grand Noble 2 (Blagnac -Alto Garona-) el peso recuperado oscila entre los 253,3 g de la tumba $n^{\circ} 2$ y 1406,8 g de la $n^{\circ} 3$ (Pons et al., 2008), en Can Piteu - Can Roqueta (Sabadell) unos pocos vasos contenían más de 400 g, pero muchos otros no alcanzaban los 100 g (Carlús et al., 2002: 160). Estudios realizados en distintas fechas en crematorios modernos, y con una muestra próxima al millar de individuos, señalan que tras la incineración de un cadáver los restos generados oscilan entre 5379 g máximo y 876 g mínimo, siendo la media de 2277,2 g. Hay disimilitudes sustanciales en función de la robustez, sexo, etc., y hay que subrayar también un comportamiento y conservación diferencial de las distintas partes anatómicas durante la cremación. La media supera a las conservadas en los depósitos protohistóricos, salvo excepciones (Lenorzer, 2006: 170 y ss), en buena parte por ser muy diferentes los objetivos y la metodología. Otros autores (Pons et al., 2008: 27) proponen que el peso de los restos de un adulto incinerado se sitúa entre 1615-1819 gramos para las mujeres y 1841-2093 g para los hombres, o según J. Mac Kinley entre 1001,5 y 2422,5 g con una media teórica de 1604,78 g; o entre los 970 y los $2630 \mathrm{~g}$ que propone Le Goff —2002- (Lorenzo y Royo, 2017).

Desconocemos cómo y dónde se efectuó la cremación, y si el procedimiento era muy estricto; o si se colocaba el cuerpo entero en la pira o lo era una vez descarnado. Son de interés, tanto por la diversidad y complejidad de rituales practicados como por la dificultad de probarlos, diversas fuentes de información,s como son los paralelos etnográficos (Le Goff, 2002; 2009; 2013), los textos de autores clásicos (de Silio Itálico, Eliano), y los vasos pintados del valle del Ebro donde se representa la exposición de los cadáveres para que ser consumidos por los buitres (Lillo-Carpio, 2001-2002). De la descripción de Millagate IV (Duday, 1988), donde los huesos de las extremidades inferiores no alcanzaron la misma temperatura que los restantes, se deduce que al menos en esas fechas tan avanzadas se depositaba el cuerpo entero en la pira.

En el caso de los huesos de Ondarre I y Oianleku (algún fragmento de diáfisis tiene la cara interior gris- 
azulada) hay que subrayar su reducido tamaño $(<3 \mathrm{~cm}$, aunque unos pocos tienen entre $4-5 \mathrm{~cm})$, y la uniformidad del color — tendente a blanco- que presentan, y que indicaría su exposición a más de $650{ }^{\circ} \mathrm{C}$ (Lenozer, 2006: 153). Presentan ese estado, en parte, de forma natural por el proceso de cremación, pero también como consecuencia de diferentes tipos de manipulaciones con el fin de acelerar la reducción del cadáver y disminuir el consumo de combustible, o incluso por haber sido parcialmente triturados. Por ejemplo, dos o tres restos hallados en el túmulo I de la necrópolis tumular del Corral de Mola (Zaragoza), presentan cortes realizados con algún objeto metálico cortante sobre hueso cremado (Lorenzo et al., 2017: 168).

También pudieron existir cambios de criterio en el tiempo. Así, en la necrópolis de incineración de Can Piteu-Can Roqueta, la fragmentación de los huesos contenidos en los vasos del Bronce Final (la mayoría < 2 $\mathrm{cm}$ ) es mayor que en los de la I Edad del Hierro, donde algunos tienen hasta 6-7 cm (Carlús et al., 2002: 161).

Por otra parte, una larga serie de crómlech no conserva restos óseos (Egiar, Ondarre II y III, Mulisko Gaina -Peñalver, 1987; 1990-, etc.), lo que se ha atribuido a problemas de conservación por la acidez de los suelos, o a que se consideren como cenotafios (Blot, 1997; 2013), quizás como los de época ibérica y romana (LiIlo Carpio, 2001-2002). Sin embargo, en el caso de las incineraciones el $\mathrm{pH}$ del sedimento no influye de forma decisiva en la conservación de los huesos como consecuencia del proceso de mineralización producido por las altas temperaturas (Mays, 1998; Lenorzer, 2006: 255). Prueba de ello son los restos incinerados del dolmen de Praalata (Idiazabal), pero donde la litología — arenisca- no ha permitido la conservación de los inhumados, salvo si existen intercalados bloques calizos, como en el dolmen de Etxegarate. Esto mismo se ha señalado en el área granítica del oeste del Macizo Central, o en el sur de Aquitania meridional donde los túmulos implantados en terrenos ácidos no conservan restos óseos, por lo que Dedet (2004: 195) plantea si no se tratarían de inhumaciones cuyos huesos no se conservan.

¿La ausencia de restos óseos en crómlech podría deberse a la práctica de la inhumación? ¿Cuándo llega la incineración y cuándo se generaliza? La situación es compleja y la respuesta objetiva de si en ciertos casos se practicaba la inhumación tendrá que venir del desarrollo de estudios geoarqueológicos, análisis de química orgánica y la recuperación de genes en el sedimento.

La existencia de este ritual de incineración en el Pirineo Occidental ha sido objeto de estudio desde la década de los años setenta, planteándose su práctica en otros contextos anteriores (cuevas, etc.), aunque la mayoría se desechan por ser cremaciones fortuitas y óxidos (Mujika-Alustiza et al., 2016). Un ejemplo excepcional es el dolmen de Ite 1 (Ébrard y Boucher, 2013) donde había $2875 \mathrm{~g}$ de huesos incinerados (de distintos colores) pertenecientes a varios individuos adultos e infantiles —una muestra ósea se dató en $3725 \pm 25$ $\mathrm{BP}$ - . Otro caso interesante es la sepultura bajo túmulo de Pomps, que en su zona central tenía un suelo de cantos rodados donde había restos de una doble incineración. Fue datada en 3850 120 BP (Blanc y BuiThi-Mai, 1988). Tras un vacío de varios siglos tenemos el cofre de Urdanarre N1 (Blot, 1993), construido probablemente durante el Bronce Antiguo, que además contiene restos de al menos una inhumación tardía de la Edad del Bronce $(2990 \pm 50$ BP) y de una incineración (99,8 g) no datada directamente, y cuya cronología desconocemos.

De la veintena de fechas del País Vasco obtenidas en crómlech (excluidas las de Ondarre) la mayoría se sitúan en la primera mitad del I milenio a.C., y las incineraciones más antiguas en torno a 2700-2800 BP, solapándose con las inhumaciones más tardías documentadas

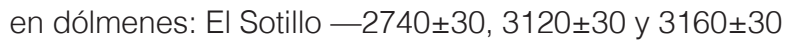
BP_, Etxegarate $-2715 \pm 45,3070 \pm 30 \mathrm{BP}-\mathrm{y}$ en la cista o cofre de Urdanarre N1 (Fernández-Eraso y Mujika-Alustiza, 2013; Mujika-Alustiza y Edeso-Fito, 2011).

Dependiendo del territorio, la incineración se incorpora más o menos tardíamente, principalmente entre el Bronce Final y comienzos de la Edad del Hierro, conviviendo durante un periodo con la inhumación. En Francia, al este de la cuenca baja del río Hérault (Provenza litoral, Alpes del sur) no hay incineraciones en el Bronce Final IIIb, mientras que sí las hay hacia el oeste en diversas necrópolis, pero subsiste la duda sobre el ritual (¿inhumación?) en los túmulos implantados en suelos ácidos del sur de Aquitania, y hay coexistencia de rituales hasta el siglo VI y primera mitad del V a.C. en cuatro casos de Gironde, Gers y Lot-et-Garonne (Dedet, 2004: 195). Por el momento no está claro el papel de los grupos continentales ni el de la influencia mediterránea en la difusión de la incineración en el Midi de Francia (Janin, 2001). La convivencia de rituales se detecta también al sur del Pirineo, como en el caso de las necrópolis de Los Castellets (Zaragoza) y la Herrería (Guadalajara), y la existencia de una inhumación en cueva (Fuentenogroso -Asturias-) fechada en 2550 \pm 40 y $2500 \pm 40$ BP (Barroso et al., 2007). Se propone que el ritual penetraría en la península por el noreste a lo largo del siglo VIII a.C. y que a lo largo del siguiente se generalizaría en el sur de Navarra, en torno al 600 a.C. (Faro, 2015: 34). En el Pirineo Occidental, y a la vista de la notable antigüedad de algunas fechas de cremaciones del entorno (Ité, Pomps), parece que habría que buscar aquí la procedencia de los grupos incineradores, independientemente de que llegaran también influencias mediterráneas. Sin embargo, la escasez de evidencias no permite profundizar en la cuestión.

\subsection{Los restos antracológicos y datos medioambientales}

Debido a la naturaleza funeraria de estos depósitos, la presencia de la madera debería de estar directa- 
mente relacionada con el ritual y ceremonias desarrolladas en los mismos. Los fuegos realizados concentrarían las maderas utilizadas, que posteriormente se depositaron en los crómlechs. En el caso que nos ocupa, pese a estar los tres yacimientos muy próximos, se aprecian diferencias en la composición de la orla representada. Así, en Ondarre I, se observa una importancia de la madera de haya y fresno muy clara (Mujika-Alustiza et al., 2016). Sin embargo, en Ondarre II y III esta visión cambia, la madera carbonizada procede de pequeñas acumulaciones y se observa aquí una mayor variabilidad a pesar de lo reducido de las muestras. Las rosáceas (de tipo pomoidea de forma mayoritaria) son las mejor representadas en Ondarre II, mientras que en Ondarre III sobresale la madera de haya junto con las rosáceas (Fig. 12). El resto de los taxones tienen una representación similar entre ellos.

Parece evidente que a tenor de la información obtenida en el entorno de Pikueta-Mendibil-Ondarre se desarrollarían extensiones de hayedos junto con robledales y bosque mixtos atlánticos, taxones que encontramos entre las maderas quemadas en los yacimientos estudiados. Junto a ellos, en las zonas más húmedas, habría alisos, por ejemplo a lo largo de la regata que recorre Ondarre, así como fresnos. Esto sugiere que se utilizaban maderas presentes en el entorno cercano. En Ondarre II y III, la variabilidad de los taxones es mayor que en Ondarre I, lo que apunta a una menor selección. En Ondarre II, aun siendo prácticamente contemporáneo, las maderas se relacionan más con especies de tipo arbustivo, que forman parte de la orla de diferentes bosques caducifolios, con un porte menor, como pueden ser las rosáceas o el avellano. Junto a ellas también se identifica madera de haya o de Quercus caducifolio. Las rosáceas constituyen un grupo de maderas densas que ofrecen alto poder calorífico, casi comparable a la del haya. Las ramas finas se podrían utilizar para conseguir temperaturas altas en poco tiempo. El calibre de la madera y su humedad serían los principales factores que condicionan el poder y el rendimiento calorífico (Costa-Tenorio et al., 1997; López-González,
1982; 2002; López-Lillo y Sánchez de Lorenzo, 1999). En Ondarre III cobra importancia la madera de haya, apreciada como combustible, y presente también en Ondarre I y II (Aizpuru et al., 1990; López-González, 2002; Oria de Rueda y Díez, 2003; Loidi, 2007).

\subsection{De testigo de crómlech a haustarri}

La coincidencia de distintos monumentos funerarios con los límites administrativos actuales plantea la cuestión de si este hecho es resultado del azar, por ubicarse en emplazamientos naturales que facilitan ese deslinde, o si por lo contrario se reutilizaron por su simbolismo o por el particular significado de la construcción en ese momento, o quizás por su función como hito ganadero, como en el caso que nos ocupa. Los cambios en la modalidad de la posesión, en el tipo de disfrute, o la adaptación a las crecientes necesidades surgidas unas veces a causa del incremento demográfico y consecuente presión sobre el medio, exigía prioritariamente reordenar y redistribuir el territorio. La figura o significado de cada monumento variaría según las circunstancias, revitalizándose su función como hito cuando se agrega otro de similar significado más moderno (dolmen-cista; cista-cromlech), y en caso necesario se incorporaban sucesivamente otros nuevos hitos polimorfos, naturales o no (Agirre et al., 2010). En otras ocasiones, estos hitos de distinta tipología se darían por amortizados, como sospechamos en el caso de los menhires desplomados (Supitaitz, Jentillarri, Igaratza, etc.), quizás no siempre por causas naturales, sino abatidos, presumiblemente, por perturbar el nuevo orden que se quiere imponer en la gestión del territorio. No se tiene constancia documental de la razón por la que se seleccionan algunos de los monumentos como mojón, pero en Ondarre III estamos ante la reutilización de un cromlech, o de uno de sus testigos, como haustarri. Por ello no podemos evitar traer a colación las palabras de Barandiaran (1972: 214) donde decía "Los seles recuerdan o reproducen la forma de los viejos crómlechs pirenaicos con su austarri <piedra cenizal> que ocupa el centro, como la urna de cenizas de muertos en aquellos monumentos".

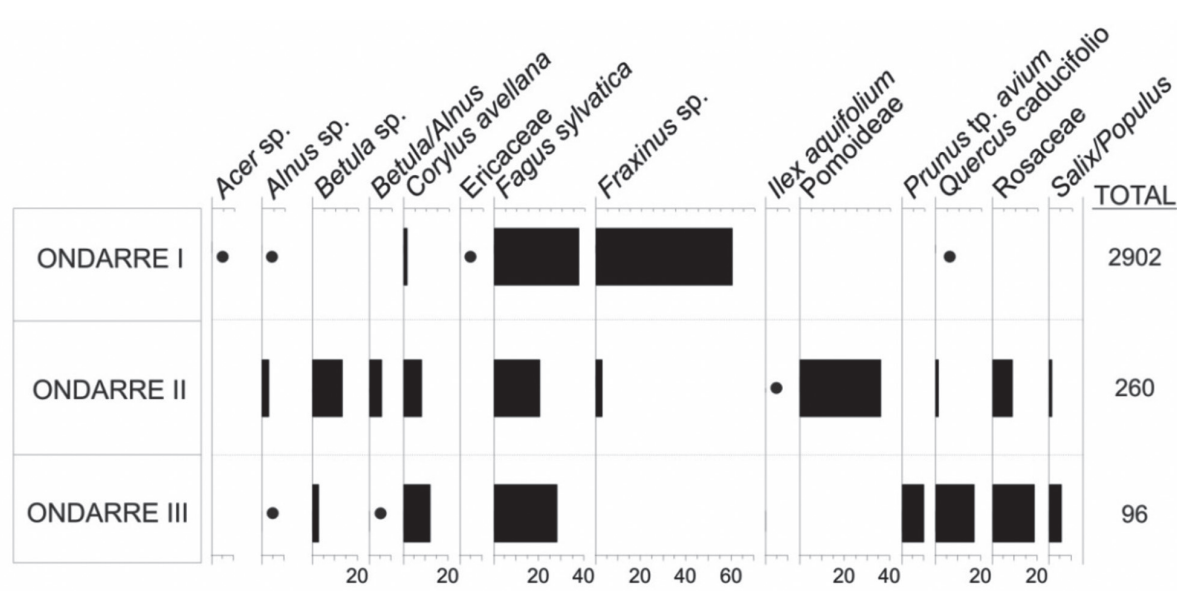

Fig. 12. Histograma antracológico de porcentajes de Ondarre I, II y III. Los puntos hacen referencia a porcentajes inferiores al $1 \%$. / Percentage anthracology histogram from Ondarre I, II and III. Points refer to percentages smaller than $\% 1$. 
Al menos desde finales de la Edad Media, los mojones cenizales (eusk. hausterretza [> haustarri] ${ }^{3}$, artamugarri, kortarri) han sido utilizados para señalizar el punto central de los espacios ganaderos de forma circular llamados seles (eusk. saroi, korta), de manera que, aplicando un radio y sirviéndose de una vara, cuerda o cadena, desde ellos se delimitaba la superficie de dichos espacios, fijándose en muchos casos en el perímetro de los mismos otros cuatro, ocho o dieciséis mojones periféricos (eusk. baztermugarri). Los hay formados por un solo bloque sin apenas trabajar (o incluso sin desbastar), y otros más complejos y más estandarizados con alguna cruz o asterisco grabado (Zaldua, 2015a: 1191). Es probable que la presencia de cruces grabadas, responda a prácticas o rituales de las que quizás se conserve alguna referencia documental ${ }^{4}$, pero difícilmente testimonio arqueológico suficientemente objetivo. Se persigue garantizar la permanencia in situ de estos discretos elementos pétreos ${ }^{5}$.

Al menos desde el siglo XV parece que hay un tipo de señalización del lugar central de los seles mediante una fogata, o quizás también una piedra. Así se dice en 1433, en Legazpi: "fogueraqu'es dicho austerraça, en derredor"; "mojón del fogar a la redonda" en 1452, en Zestoa, etc. (Díez de Salazar, 1993: 208-211; Ayerbe y Elorza, 2008: 78). Hay que advertir que el fuego tiene un notable protagonismo ya desde época prehistórica, y su presencia, aunque no siempre, se constata en distintos tipos de contextos funerarios (testigos del baratze y en el interior de la cista de Ondarre, etc.), domésticos (preparación de comida ${ }^{6}$, en procesos de purificación, etc.) y agrícolas (la tierra de cultivo se ganaba al bosque mediante la tala y posterior quema del suelo), y era un elemento de cohesión social, entre otras, por ejemplo en las mejor documentadas sociedades mediterráneas (Gracia-Alonso, 2001). Ese papel se prolongará hasta fechas históricas, tanto en contextos religiosos, como domésticos, socioeconómicos (unidad fiscal), y también en el ámbito ganadero, donde la "foguera" es, junto con el mojón, elemento protagonista en la verificación de los seles. A partir de la Baja Edad Media se consolidará, y complementará a otro tipo de pruebas vigentes hasta esa fecha (por ejemplo testigos vivos, presencia de restos construcciones, indicios de actividad antrópica —Zaldua, 1996-), aunque desconocemos la jerarquía probatoria de estos elementos en los litigios. Colocar carbones al pie de mojones de término es una práctica generalizada, citándose en el deslinde del Pirineo - Tratado de Elizondo_ - a finales del siglo XVIII (Capdevila, 2009); y en Paris, quizás desde finales de la Edad Media (Roux, 1995). En otras ocasiones, a partir del siglo XVIII (?), junto a los carbones se depositarán también trozos de teja o de ladrillo, como señalan autores de principios del siglo XX (Barandiaran, 1972), y como se ha comprobado en los haustarris de Lanbarren, Oiartzun, y Lizundia, Elgoibar, (Arruabarrena et al., 2014; Zaldua et al., 2015). Quizás fuera el resultado de una relectura del derecho romano y de la simbología del dios Terminus (Álvarez, 2011; Armstrong, 17817; Moreri, 1753), que se revitaliza, pero que no parece haber estado en uso de forma estricta a lo largo de la Edad Media, al menos a la luz de los resultados arqueológicos obtenidos en los mojones ganaderos de este entorno geográfico.

Constatamos que en determinados emplazamientos de Aralar (Pikueta-Argarbi por ejemplo) se conservan, en un reducido espacio, tanto monumentos megalíticos como estructuras históricas (romanas, medievales, etc.), además de otras de cronología incierta, como ya apunta Barandiaran (1972). La explotación de los recursos ahí se ha realizado de forma ininterrumpida desde el Neolítico hasta la actualidad, pero faltan parcialmente los eslabones arqueológicos asociables a sus respectivos contextos históricos para tratar de hil-

\footnotetext{
3 "De la piedra cenizal e austarri de donde el dicho sel se suele medir" (Zenarruza, 1556) (Isasi et al., 2005, 93).

${ }^{4}$ En los documentos notariales bajomedievales españoles, el ritual de posesión para un terreno de cultivo de cereal es hacer un agujero con la azada (como cimiento) y colocar un montón de piedras en él, a modo de mojón; en los lugares de arbolado o vides, se cortaban ramas o sarmientos, según el caso (los sarmientos por su carácter sagrado en la misa, se colocaban a veces en el suelo sobre el que se construía una casa); y en el caso de las casas además de "echar" de la casa al anterior posesor, se entraba y se paseaba por la casa, se abrían y cerraban puertas y ventanas, y se entregaba la llave: "El concepto de llave va parejo al sentido físico de la casa, ya que lo que se posee, en principio, no es el espacio habitable, cuyo símbolo era el fuego y la luz sino el material" (Puñal, 2002: 133-135).

${ }^{5}$ En la segunda mitad del siglo XV las revisiones de mojones y montes y caminos concejiles y los amojonamientos se multiplican en la documentación escrita de las villas. En ella se revisan los mojones de término y sus testigos y las señales en forma de cruz que algunos llevan en los costados para ver si están bien colocados y limitaban los terrenos con otras jurisdicciones colocando mojones y estableciendo las penas por quitarlos. El propio corregidor de Bizkaia como representante real, tenía la obligación de revisar los términos jurisdiccionales y los mojones cada dos años por orden real (Hidalgo de Cisneros et al., 1989: 437, 467-472, 494).

${ }^{6}$ El Orotariko Euskal Hiztegia (Michelena, 1987) en el término de haustarri recoge las definiciones del Diccionario de Azkue: Autsarri: Piedra cenizal en medio de los seles, donde antiguamente se hacía la comida" en Bizkaia y Austarri: Piedra cenizal (hogar rústico) en el centro de un sel" —citado a su vez de la Historia de Vizcaya de Iturriza. pág. 76-. Arin (1955: 89) recoge el significado de Austarrie en el caserío Erzillegi -Ataun- (para Aralar) y Barandiaran (1955: 188) el de Austarri (piedra cenizal) en Gamiz y Morga, y korta-arri (piedra de sel) en Berriatua.

7 Se sabe que los Romanos se fingieron un Dios Término para guardar los límites, o separaciones de sus tierras. Las fiestas terminales que celebraban el veinte y dos, o el veinte y tres de Febrero, fueron instituidas en honor suyo: se ofrecía pan, frutos, igualmente que otros animales domésticos: se le veía, ya bajo la figura de una teja, en una piedra quadrada ( $\mathrm{sic}$ ), o en una estaca clavada en la tierra; ya bajo la figura de un viejo, en un simple busto, sin brazos, puesto sobre un pedestal, que iba en disminución hasta la basa, bajo la cual se ponía ordinariamente carbón. Esta substancia pasaba por incorruptible en la tierra; y el uso que se hacía en esta ocasión alegórico a las leyes, que prohibían como una acción impía, mudar o trastornar los términos de los territorios... (Armstrong, 1781: 9-10).
} 
vanar ese pasado. Las primeras modificaciones en la gestión del paisaje se produjeron en la Edad de los Metales, al construir nuevos dólmenes, cistas y crómlech. Dada la continuidad del poblamiento, sin rupturas drásticas, la transmisión de la gestión de los recursos del territorio (¿o éste mismo?), así como su reconocimiento, se produciría a través de las diferentes modalidades de sepulturas que destacan en ese paisaje de montaña. Sin embargo, por la dinámica del poblamiento y de sus características, y al compás del discurrir de los hechos históricos (grupos norpirenaicos durante la Edad del Hierro, periodo romano -Zaldua 2018-, etc.) y de las transformaciones culturales y socioeconómicas, el proceso señalizador y reivindicativo conocería mecanismos de adaptación y/o de cambio. Es inevitable preguntarse si el abandono del uso funerario de esos monumentos ocasionó simultáneamente la atenuación, que no el olvido, de su significado y simbolismo. La aparición de nuevas manifestaciones funerarias caracterizadas por su menor visibilidad pudo motivar el desarrollo o expansión del uso de nuevos hitos antrópicos formalizados, más o menos perennes (fogatas, pequeños o medianos bloques de piedra), cuyos primeros ejemplares pudieron situarse en aquellas zonas disponibles, todavía no explotadas tan recurrentemente. Otras veces vendrían a sustituir al antiguo, colocándolo junto a él, o en sus proximidades, reforzando al primero, o por el contrario en otro lugar con el fin de definir la nueva ordenación del territorio.

La reutilización de uno de los testigos del crómlech Ondarre III como haustarri es un hecho muy relevante, pero las pruebas no son definitivas. Creemos que estamos ante un ejemplo de la prolongación de la función de hito ganadero que tuvo la estructura funeraria desde su construcción durante el Bronce Final, y que se transfirió, o se focalizó, su función y simbolismo en su testigo más relevante - que, además, evoca a un menhir pequeño-, en una fecha no precisable.

\section{CONCLUSIONES}

El valle de Ondarre muestra ocupación a lo largo de la Edad del Bronce e inicios de la Edad del Hierro. Hasta ahora no se habían localizado aquí monumentos funerarios (una cista y tres baratze o crómlech de incineración), seguramente porque su litología los ha enmascarado y ha dificultado su conservación. Los bloques utilizados en su construcción tienen un origen local. Encontramos calizas fétidas presumiblemente vinculadas a las calizas negras estratificadas (calizas de Sérpulas) del Jurásico terminal-Neocomiense (coinciden con los relieves dominantes) y también bloques de calizas bioclásticas y calizas arenosas (puntualmente conglomeráticas) procedentes del Malm II (afloran en el fondo de la depresión), así como algunos bloques de calizas dolomíticas del Dogger (laderas orientales de Ondarre).

Ondarre I fue el primero de los tres crómlechs excavados y en su centro se hallaron restos óseos inci- nerados de dos personas juveniles y una gran mancha de carbón. La cantidad de huesos incinerados indica que se depositaba una parte simbólica. Junto a los testigos se localizaron también algunos elementos, quizás, relacionados con el ritual (un canto rodado - posible percutor o mano de molino-, algún fragmento de cerámica y carbones).

Se excavaron también Ondarre II y III, hallando manchas carbonosas, algún sílex, pero ningún resto óseo. La repetida ausencia de restos óseos incinerados ha llevado a Blot a proponer que pudieran ser cenotafios, pero contemplamos la posibilidad de que correspondieran a inhumaciones cuyos huesos no se conservan por la acidez de los suelos. Las fechas los sitúan en la primera mitad del I milenio a.C.

El paisaje que rodearía estos monumentos se caracterizaba por la presencia de bosques caducifolios bastante desarrollados, con especies como avellanos y robles y en menor medida alisos, fresnos, sauces, abedules, hayas y tilos, según nos indica la palinología. De todo el cortejo arbóreo, hayas, fresnos y rosáceas de tipo Pomoideae (junto con el avellano en Ondarre III) eran los preferidos y eminentemente utilizados en las actividades desarrolladas en estas estructuras funerarias, según documenta el estudio antracológico. A pesar de esta presencia de bosques, el paisaje refleja evidencias de antropización, pero no se detectan especies cultivadas.

Uno de los testigos de Ondarre III se documenta ya desde los siglos XVIII-XIX reutilizado como haustarri o piedra de sel. Creemos que la estructura funeraria fue originalmente también un hito espacial, y que a raíz de los cambios producidos en el método de señalización en época romana, o siguiendo su tradición en época medieval, se transfirió esa función al nuevo tipo de hito recientemente adoptado (un mojón o un bloque pequeño). Concretar este momento es difícil, pero parece situarse en una fecha previa al momento en que se dispone un haustarri formalizado con un hogar, probablemente en época romana o altomedieval.

Mediante este trabajo queda abierta, por un lado, la búsqueda de nuevos elementos funerarios de esta tipología en zonas en las que no son conocidas; y, por otro, la necesidad de profundizar en la relación de estos elementos funerarios del Bronce Final-Edad del Hierro con marcadores del territorio posteriores, que en ocasiones han perdurado hasta la época contemporánea en forma de haustarri, como ocurre con el testigo de Ondarre III.

\section{AGRADECIMIENTOS}

Los trabajos de campo realizados en el crómlech de Ondarre han sido subvencionados por la Diputación Foral de Gipuzkoa. El estudio se ha desarrollado en el Grupo de Investigación del Sistema Universitario Vasco IT-622-13 y el proyecto del Ministerio de Ciencia e Inno- 
vación (HAR2015-67429-P). Mónica Ruiz-Alonso está financiada por el Programa Estatal de Promoción del Talento y su Empleabilidad en I+D+i en la modalidad Juan de la Cierva-Formación, Sebastián Pérez-Díaz por el Programa Estatal de Promoción del Talento y su Empleabilidad en I+D+i en la modalidad Juan de la Cierva-Incorporación, Erik Arevalo-Muñoz por el Programa Predoctoral del Departamento de Educación, Política Lingüística y Cultura del Gobierno Vasco $\left(n^{\circ}\right.$ de referencia PRE_2014_1_337) y Daniel Ruiz-Gonzalez por el programa de Formación de Profesorado Universitario (FPU) del Ministerio de Educación, Cultura y Deporte del Estado Español (nº de referencia FPU16/07266).

Queremos mostrar nuestro agradecimiento a todos aquellos que han colaborado en los trabajos de campo (Gailurraruntz Mendi Elkartea, Xabier Etxeberria, J. A. Irastorza, miembros del Grupo Munibe -J. Alberdi, J. M. Arruabarrena, M. Sasieta-, Giorgio Studer, Lontxo Ugarte, etc.) y a los revisores de la revista porque sus aportaciones han permitido la mejora del artículo.

\section{BIBLIOGRAFÍA}

Agirre, J., Moraza, A., Mujika, J.A., Zaldua, L.M., 2010. Sondeos en la Sierra de Aralar (Unión Enirio Aralar). Arkeoikuska 2009, 404-407.

Aizpuru, I., Catalán, P., Garín, F., 1990. Guía de los árboles y arbustos de Euskal Herria. Gobierno Vasco, Vitoria-Gasteiz.

Álvarez Catalá, S., 2011. Bajo La Advocación Del Dios Terminus. Debate Terminológico 7, 78-79.

Arevalo, E., Edeso, J.M., Goikoetxea., I, Lopetegi, A., Mujika, J.A., Orue, I., Zaldua L.M., 2015. Sierra de Aralar. Arkeoikuska 2014, 373-377.

Arin Dorronsoro, J., 1955. Notas acerca del pastoreo tradicional de Ataun, Anuario Eusko Folklore 15, 87-122.

Armstrong, J., 1781. $\mathrm{H}^{\mathrm{a}}$ Civil y Natural de la Isla de Menorca: descripción topográfica de la ciudad de Mahón y demás poblaciones, Madrid.

Arruabarrena, J.M., Mujika-Alustiza, J.A., Zaldua, L.M., Arranz, A., 2014. Lanbarrengo industrialdeko haustarria. Mojón del polígono industrial de Lanbarren. Arkeoikuska 13, 321-322.

Ayerbe, M.R., Elorza, J., 2008. Archivo Municipal de Zestoa (1338-1520). Eusko Ikaskuntza, Donostia.

Barandiaran, J.M. DE, 1955. Notas sueltas sobre el pastoreo en Gorbea, Anuario Eusko Folklore 15, 185-190.

Barandiaran, J. M., 1972. Diccionario llustrado de Mitología Vasca. Obras Completas I, Ed. La Gran Enciclopedia Vasca, Bilbao.

Barroso, R., Bueno, P., Camino, J., De Balbín, R., 2007. Fuentenegroso (Asturias), un enterramiento del Bronce Final en el marco de las comunidades atlánticas peninsulares. Pyrenae 38(2), 7-32.

Blanc, Cl., Bui-Thi-Mai, 1988. Une double sépulture Chalcolithique sous tumulus, et son paléoenvironment (Pomps, P.A.). Munibe Antropologia-Arkeologia 40, 71-82.

Blot, J., 1977. Les cromlechs d'Errozate et d'Okabe (Basse Navarre) (compte-rendue de fouilles). Munibe 29, 77-96.
Blot, J., 1988. Le Tumulus-Cromlech de Millagate IV. Munibe 40, 95-103.

Blot, J., 1991. Le Tumulus-Cromlech de Millagate V. Munibe 43, 181-189.

Blot, J., 1993. Le tumulus Urdanarre Nord 1. Munibe 45, 143-151.

Blot, J., 1997. Círculos de piedras (o baratze) en el País Vasco Norte. Kobie XXIV, 33-67.

Blot, J., 2013. Les tumulus-cromlechs de Millagate (Miragarate) IV et $V$ à Larrau. 50 ans d'archéologie en Soule. Hommage à Pierre Boucher (1909-1997). Ikerzaleak 7, 213-226, Mauleon.

Blot, J., Raballand, R., 1995. Contribution à l'étude des cercles de pierres en Pays Basque de France. Bulletin de la Société préhistorique française 92, 525-548.

Burjachs, F., López-Sáez, J.A., Iriarte, M.J., 2003. Metodología Arqueopalinológica. En: Buxó, R. y Piqué, R. (eds.), La recogida de muestras en Arqueobotánica: objetivos y propuestas metodológicas. La gestión de los recursos vegetales y la transformación del paleopaisaje en el Mediterráneo occidental, 1118. Museu d'Arqueologia de Catalunya, Barcelona.

Capdevila I Subirana, J., 2009. Historia del deslinde de la frontera hispano-francesa. Del tratado de los Pirineos (1659) a los tratados de Bayona (1856-1868). Instituto Geográfico Nacional, Ministerio de Fomento.

Carlús, X., Lara, C., López Cachero, J., Villena, N., 2002. La necrópolis de incineración de Can Piteu-Can Roqueta (Sabadell, Barcelona): caracterización del ritual funerario. Bolskan 19, 141-164.

Costa Tenorio, M., Morla Juaristi, C., Sainz Ollero, H., 1997. Los bosques ibéricos. Una interpretación geobotánica. Ed. Planeta, Barcelona.

Dedet, B., 2004. Variabilité des pratiques funéraires protohistoriques dans le sud de la France: défunts incinérés, défunts non brûlés. Gallia 61, 193-222.

Díez de Salazar, L.M., 1993. Colección Diplomática del Concejo de Segura (Guipúzcoa) (1290-1500). Tomo II (1401-1450). Eusko Ikaskuntza, Donostia/San Sebastián.

Duday, H., 1988. Le Tumulus-Cromlech de Millagate IV. Etude des Restes Humains. Munibe Antropologia-Arkeologia 40, 105-110.

Ébrard, D., Boucher, P., 2013. Le dolmen d'Ite 1 à Aussurucq (Pyrénées-Atlantiques). En: 50 ans d’archéologie en Soule. Hommage à Pierre Boucher (1909-1997), 173-186. Ikerzaleak 7. Mauleon.

Edeso, J.M., Goikoetxea, I., Lopetegi, A., Arevalo, E., Mujika, J.A., 2014. Sierra de Aralar: Ondarre e Igaratza. Arkeoikuska 2013, 328-331.

Edeso-Fito, J.M., Goikoetxea-Zabaleta, I., Lopetegi-Galarraga, A., Arévalo-Muñoz, E., Orue, I., Zaldua, L.M., Mujika-Alustiza, J.A., 2016. Contribution to the study of the geographical distribution of Pyrenean funerary stone circles -baratze, cromlechin the western Pyrenees. Zephyrus LXXVII, 193-205.

Faro, J.A., 2015. La necrópolis de El Castillo (Castejón, Navarra). Vajilla e instrumental metálico de sacrificio y banquete en el valle medio del Ebro (s. VI-III A. C.). Lvcentvm XXXIV, 31-118.

Fernández-Eraso, J., Mujika-Alustiza, J.A., 2013. La estación megalítica de La Rioja Alavesa: cronología, orígenes y ciclos de utilización. Zephyrus LXXI, 89-106. 
Girard, M., Renault-Miskovsky, J., 1969. Nouvelles techniques de préparation en palynologie appliquées à trois sédiments du Quaternaire final de l’Abri Cornille (Istres, Bouches du Rhône). Bulletin de l'Association Française pour l'Etude du Quaternaire 1969(4), 275-284.

Goeury, C., Beaulieu, J.L., 1979. Á propos de la concentration du pollen à l'aide de la liqueur de Thoulet dans les sédiments minéraux. Pollen and Spores 21, 239-251.

Gracia Alonso, F., 2001. El fuego como referente de culto. Datos de la protohistoria peninsular mediterránea. Cypsela 13, 101-122.

Hather, J. G., 2000. The Identification of the Northern European Woods. A Guide for Archaeologists and Conservators. Archetype Publications, Londres.

Hidalgo de Cisneros Amestoy, C., Lagarcha Rubio, E., Lorente Ruigomez, A., Martinez Lahidalga, A. 1989. Colección documental del Archivo Municipal de Durango. Fuentes documentales medievales del País Vasco 20, 21, 22 y 23. Eusko Ikaskuntza, San Sebastián.

Isasi Martínez, C., Álvarez Carrero, D., Gancedo Negrete, S., Gómez Seibane, S., Gómez Fernández, J., Ramírez Luengo, J.L., Romero Andonegi, A., 2005. Léxico vizcaíno (siglos XIVXVI). Oihenart 20, 73-201.

Janin, Th., 2001. Sépultures, nécropoles, archéologie funéraire et sociétés de l'âge du Bronze dans le Sud-Ouest de la France. Documents d'archéologie méridionale 24, 230-237.

Le Goff, I., 2002. Les vestiges de la crémation: témoins privilégies des protocoles funéraires. Archéopages 6, 10-17.

Le Goff, I., 2009. Le devenir du cadavre incinéré en Gaule Belgique. Méthodes et analyse de cas. Revue Archéologique du Picardie 3-4, 113-127

Le Goff, I., 2013. Cadavre et crémation. In : Guy, H., Jeanjean, A. y Richier, A. (Eds.), Le Cadavre en procès, 92-109.Techniques \& Culture 60.

Lenorzer, S., 2006. Pratiques funéraires du Bronze final IIllb au premier âge du Fer en Languedoc occidental et Midi-Pyrénées: approche archéo-anthropologique des nécropoles à incinération. Thèse de doctorat. Université Bordeaux I. Lab. d’Anthrop. des Populations du Passé, UMR 5199 PACEA.

Lillo Carpio, P.A., 2001-2002. Notas acerca de la incineración. Anales de Prehistoria y Arqueología 17-18, 127-146.

Loidi, J. J., 2007. La evolución del paisaje vegetal del centro-norte de la Península Ibérica a lo largo de la historia. Lección de ingreso como amigo de número. Boletín de la Real Sociedad Bascongada de los Amigos del País. Suplemento 11-B.

Lopetegi-Galarraga, A., Edeso-Fito, J.M., Mujika-Alustiza, J. A., 2012. El relleno Pleistoceno de la depresión de Ondarre (Sierra de Aralar, Gipuzkoa). En: González Díez, A. (Coord.), XII Reunión Nacional de Geomorfología, 413-417. Universidad de Cantabria.

López González, G., 1982. La guía Incafo de los árboles y arbustos de la Península Ibérica. INCAFO.

López González, G., 2002. Guía de los árboles y arbustos de la Península Ibérica e Islas Baleares. Ediciones Mundi-Prensa, Madrid.

López Lillo, A., Sánchez de Lorenzo Cáceres, J.M., 1999. Árboles en España. Manual de identificación. Mundi Prensa Libros S.A., Madrid.

Lorenzo Lizalde, J.I., Royo Guillén, J.I., 2017. Estudio antropológico de las incineraciones de la Necrópolis Tumular del Corral de Mola (Uncastillo, Zaragoza). CuPAUAM 43, 165-177.

Mays, S., 1998. The archaeology of human bones. Routledge, London.
Michelena, L., 1987. Diccionario general vasco/ Orotariko Euskal Hiztegia. Euskaltzaindia, Bilbao. Disponible en: http://www. euskaltzaindia.eus/index. php?option=com_content\&view=article\&id=276\&ltemid=413\&lang=eu

Moreri, L., 1753. El gran diccionario histórico, o miscelánea curiosa de la historia sagrada y profana. París.

Mujika-Alustiza, J.A., Agirre-García, J., Arévalo-Muñoz, E., Edeso-Fito, J.M., Goikoetxea-Zabaleta, I., Lopetegi-Galarraga, A., Orue-Beltran de Heredia, I., Pérez-Díaz, S., Ruiz-Alonso, M., Zaldua-Etxabe, L., 2016. El ritual de incineración en el cromlech tumular de Ondarre I (Sierra de Aralar -Gipuzkoa). Munibe Antropologia-Arkeologia 67, 51-73.

Mujika-Alustiza,. J.A, Edeso-Fito, J. 2011. Lehenengo nekazari-abeltzainak Gipuzkoan Neolitotik Burdin Arora. Los primeros agricultores y ganaderos en Gipuzkoa del Neolítico a la Edad del Hierro. Diputación de Gipuzkoa.

Oria de Rueda, J.A., Díez, J., 2003. Guía de árboles y arbustos de Castilla y León. Cálamo, Palencia.

Peñalver, X., 1987. Mulisko gaineko indusketa arkeologikoa (Urnieta-Hernani.Gipuzkoa). Munibe 19, 93-120.

Peñalver, X., 1990. El ritual funerario en los crómlech pirenaicos según los últimos trabajos en el conjunto megalítico de Mulisko Gaina. Zephyrus 43, 131-136.

Peñalver, X., 2005 Los crómlech pirenaicos. Bolskan 22, 11-349.

Pons, Fr., Bruxelles, L., Georges, P., Lagarrigue, A., 2008. Une nécropole protohistorique à incinération dans le Toulousain : le site de Grand Noble 2 à Blagnac (Haute-Garonne). Documents d'archéologie méridionale 31, 153-170.

Puñal, T., 2002. Análisis documental de los rituales de posesión en la Baja Edad Media. Espacio, Tiempo y Forma. Serie III Historia Medieval 15, 113-148.

Roux, S., 1995. Bornes et limites dans Paris à la fin du Moyen Âge. Médiévales 28, 129-137.

San Jose Santamarta, S., Peñalver, X., 2009. Hábitat y mundo funerario del Bronce final y la Edad del Hierro en Gipuzkoa: Problemática actual. En: Llanos, A. (Coord.), Medio siglo de arqueología en el Cantábrico Oriental y su Entorno: Actas del Congreso Internacional (1. 2007. Vitoria), 895-910.

Schweingruber, F.H., 1990. Microscopic Wood Anatomy. Swiss Federal Institute for Forest, Snow and Landscape Research.

Vegas, J.I., 2001. El crómlech de Mendiluce. Euskonews \& Media aldizkaria 121. zenbakia, Gaiak 02 atala. Disponible en: http://www.euskonews.com/0121zbk/gaia12102es.html.

Vegas, J.I., 2002. Cromlech de Mendiluce. Musar 12, 76-80. Enza S. C.

Vernet, J.L., Ogereau, P., Figueiral, I., Machado, C., Uzquiano, P., 2001. Guide d'identification des charbons de bois préhistoriques et récents: sud-ouest de l'Europe: France, Péninsule Ibérique et îles Canaries. CNRS Editions, París.

Zaldua, L.M., 1996. Saroeak Urnietan: saroeen inguruko ikerketak zertan diren Euskal Herrian. Urnietako Udala.

Zaldua, L.M., 2015. Basque saroiak. In (Clive L. N. Ruggles ed.): Handbook of Archaeoastronomy and Ethnoastronomy, Springer, New York, 1187-1195.

Zaldua, L.M., Alberdi, J., Arruabarrena, J.M., Mujika-Alustiza, J.A., 2015. Lizundia (Elgoibar). Arkeoikuska14, 231-233.

Zaldua Etxabe, Luis Mari, 2018. Onomastikaren ekarpena populatzearen berreraiketan Euskal Herrian. Anuario del Seminario de Filología Vasca «Julio de Urquijo» International, 52, 1-2, 867-898. 